University of Nebraska - Lincoln

DigitalCommons@University of Nebraska - Lincoln

Nutrition and Health Sciences -- Faculty

Publications

Nutrition and Health Sciences, Department of

4-23-2021

\title{
Early satellite cell communication creates a permissive environment for long-term muscle growth
}

\author{
Kevin A. Murach \\ University of Kentucky \\ Bailey D. Peck \\ University of Kentucky \\ Robert A. Policastro \\ University of Indiana \\ Ivan J. Vechetti \\ University of Kentucky \\ Douglas W. Van Pelt \\ University of Kentucky
}

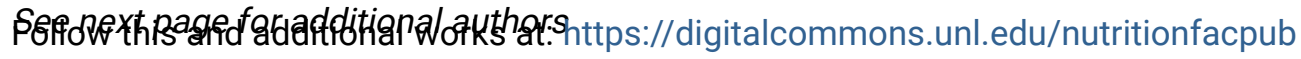

Part of the Human and Clinical Nutrition Commons, Molecular, Genetic, and Biochemical Nutrition

Commons, and the Other Nutrition Commons

Murach, Kevin A.; Peck, Bailey D.; Policastro, Robert A.; Vechetti, Ivan J.; Van Pelt, Douglas W.; Dungan, Cory M.; Denes, Lance T.; Fu, Xu; Brightwell, Camille R.; Zentner, Gabriel E.; Dupont-Versteegden, Esther E.; Richards, Christopher I.; Smith, Jeramiah J.; Fry, Christopher S.; McCarthy, John J.; and Peterson, Charlotte A., "Early satellite cell communication creates a permissive environment for long-term muscle growth" (2021). Nutrition and Health Sciences -- Faculty Publications. 260.

https://digitalcommons.unl.edu/nutritionfacpub/260

This Article is brought to you for free and open access by the Nutrition and Health Sciences, Department of at DigitalCommons@University of Nebraska - Lincoln. It has been accepted for inclusion in Nutrition and Health Sciences -- Faculty Publications by an authorized administrator of DigitalCommons@University of Nebraska Lincoln. 


\section{Authors}

Kevin A. Murach, Bailey D. Peck, Robert A. Policastro, Ivan J. Vechetti, Douglas W. Van Pelt, Cory M.

Dungan, Lance T. Denes, Xu Fu, Camille R. Brightwell, Gabriel E. Zentner, Esther E. Dupont-Versteegden, Christopher I. Richards, Jeramiah J. Smith, Christopher S. Fry, John J. McCarthy, and Charlotte A.

Peterson 


\section{Article \\ Early satellite cell communication creates a permissive environment for long-term muscle growth}

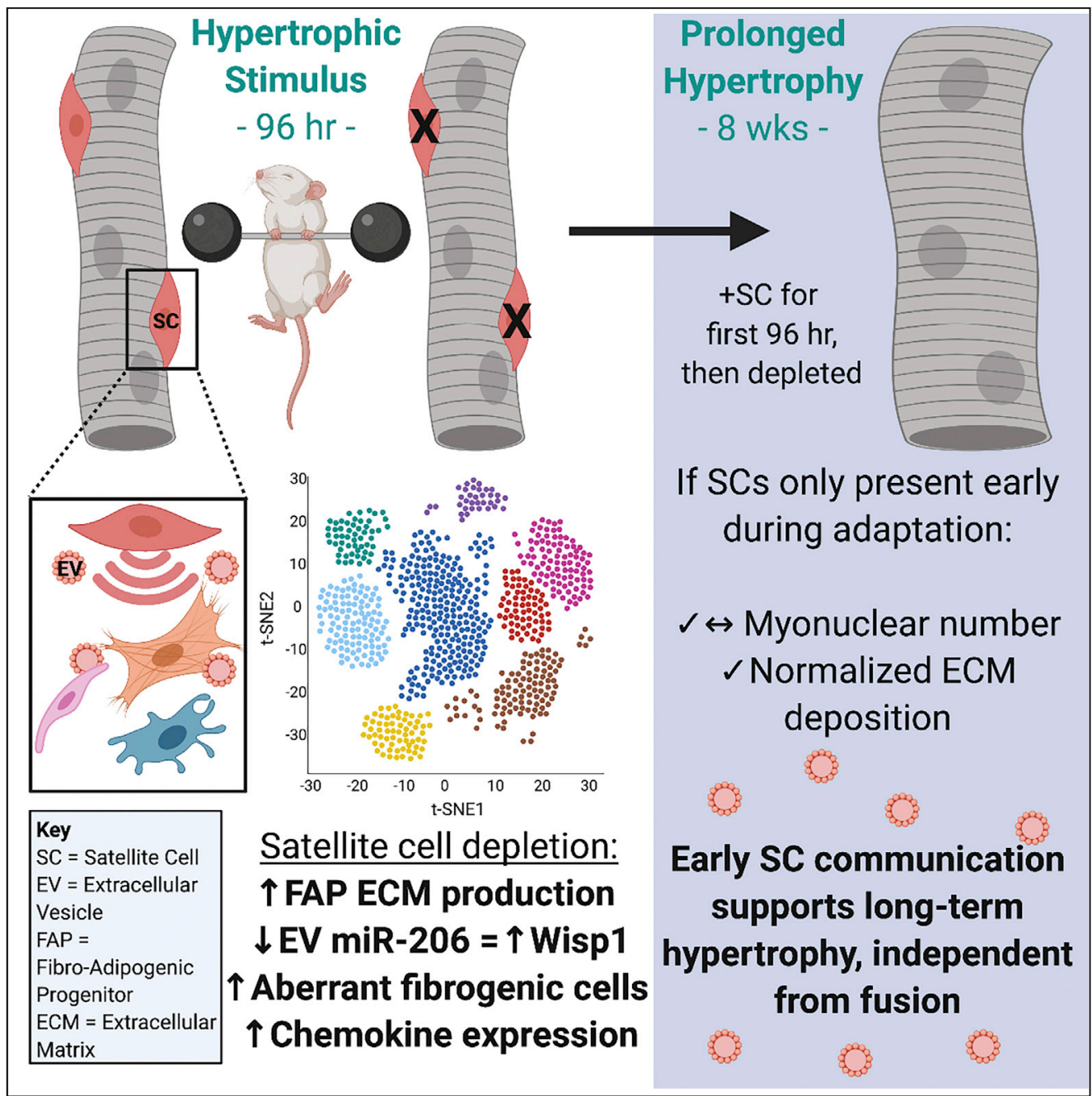

Kevin A. Murach,

Bailey D. Peck,

Robert A.

Policastro, ...,

Christopher S. Fry, John J. McCarthy,

Charlotte A.

Peterson

jjmcca2@uky.edu (J.J.M.) cpete4@uky.edu (C.A.P.)

Highlights

Widespread myogenic cell communication in

muscle during mechanical

overload (MOV)

Extracellular vesicles from myogenic progenitors repress Wisp 1 in

fibrogenic cells

Fibrogenic fate and chemokines are

influenced by satellite cells early during MOV

Prior to fusion, satellite cell communication regulates long-term hypertrophy 


\title{
Article \\ Early satellite cell communication creates a permissive environment for long-term muscle growth
}

\author{
Kevin A. Murach, ${ }^{1,2}$ Bailey D. Peck, ${ }^{1,2}$ Robert A. Policastro, ${ }^{3}$ Ivan J. Vechetti, ${ }^{1,4,5}$ Douglas W. Van Pelt, ${ }^{1,2}$ \\ Cory M. Dungan, ${ }^{1,2}$ Lance T. Denes, ${ }^{6}$ Xu Fu, ${ }^{7}$ Camille R. Brightwell, ${ }^{1,8}$ Gabriel E. Zentner, ${ }^{3}$ \\ Esther E. Dupont-Versteegden, ${ }^{1,2}$ Christopher I. Richards, ${ }^{7}$ Jeramiah J. Smith, ${ }^{9}$ Christopher S. Fry, ${ }^{1,8}$ \\ John J. McCarthy, ${ }^{1,4, \star}$ and Charlotte A. Peterson ${ }^{1,2,4,10, *}$
}

\section{SUMMARY}

Using in vivo muscle stem cell (satellite cell)-specific extracellular vesicle (EV) tracking, satellite cell depletion, in vitro cell culture, and single-cell RNA sequencing, we show satellite cells communicate with other cells in skeletal muscle during mechanical overload. Early satellite cell EV communication primes the muscle milieu for proper long-term extracellular matrix (ECM) deposition and is sufficient to support sustained hypertrophy in adult mice, even in the absence of fusion to muscle fibers. Satellite cells modulate chemokine gene expression across cell types within the first few days of loading, and EV delivery of miR206 to fibrogenic cells represses Wisp1 expression required for appropriate ECM remodeling. Late-stage communication from myogenic cells during loading is widespread but may be targeted toward endothelial cells. Satellite cells coordinate adaptation by influencing the phenotype of recipient cells, which extends our understanding of their role in muscle adaptation beyond regeneration and myonuclear donation.

\section{INTRODUCTION}

Tissue remodeling is a multi-faceted, multi-phasic process involving the coordinated regulation of numerous cell types (Farup et al., 2015; Wosczyna and Rando, 2018). Cellular choreography early in response to stress, specifically with respect to extracellular matrix (ECM) deposition and inflammatory signaling, generally determines whether long-term homeostasis is properly restored (Adler et al., 2020). In skeletal muscle, Pax7+ satellite cells mediate myonuclear accretion during muscle fiber growth (Bachman et al., 2018; McCarthy et al., 2011) and in response to exercise irrespective of growth (Masschelein et al., 2020; Murach et al., 2020b). Satellite cells may also play an important role in muscle adaptation by regulating various cell types via secreted factors (Chazaud et al., 2003; Christov et al., 2007; Fry et al., 2014a; Liu et al., 2015; Murphy et al., 2011; Patsalos et al., 2017; Tatsumi et al., 2009; Verma et al., 2018). With mechanical loading-induced skeletal muscle hypertrophy, numerous lines of evidence across different species suggest that muscle fibers can adapt and grow appreciably without satellite cell fusion and myonuclear accretion (Murach et al., 2018a); however, long-term hypertrophy without satellite cells is attenuated concomitant with excess ECM accumulation (Fry et al., 2014a). Our laboratory recently showed that satellite cells may communicate with fibrogenic cells (Fry et al., 2017) and muscle fibers (Murach et al., 2020c) via miRNA-containing extracellular vesicles (EVs) to regulate the muscle fiber milieu during hypertrophy. Presently, it is unclear whether early satellite cell-mediated secretory signaling throughout muscle is sufficient for long-term adult muscle hypertrophy or whether myonuclear addition is required to sustain hypertrophy.

In the current investigation, we utilize fluorescence-activated cell sorting (FACS), single-cell RNA sequencing (scRNA-seq), cell fate prediction analyses, inducible satellite cell depletion (McCarthy et al., 2011), in vivo EV tracking (Murach et al., 2020c), long-term mechanical overload (MOV), and in vitro approaches to explore satellite cell communication throughout muscle during load-induced hypertrophy. We provide evidence that satellite cell communication to fibroadipogenic progenitor cells (FAPs) during

\footnotetext{
${ }^{1}$ The Center for Muscle Biology, University of Kentucky, Lexington, KY 40536, USA

2Department of Physical Therapy, College of Health Sciences, University of Kentucky, Lexington, KY 40536, USA

${ }^{3}$ Department of Biology, College of Arts and Sciences, University of Indiana, Bloomington, IN 47405, USA

${ }^{4}$ Department of Physiology, College of Medicine, University of Kentucky, Lexington, KY 40536, USA

${ }^{5}$ Department of Nutrition and Health Sciences, College of Education and Human Sciences, University of Nebraska, Lincoln, NE 68588, USA

${ }^{6}$ Department of Molecular Genetics and Microbiology, Center for Neurogenetics, University of Florida, Gainesville, FL 32611, USA

7 Department of Chemistry, College of Arts and Sciences, University of Kentucky, Lexington, KY 40536, USA

${ }^{8}$ Department of Athletic Training, College of Health Sciences, University of Kentucky, Lexington, KY 40536, USA

${ }^{9}$ Department of Biology, College of Arts and Sciences, University of Kentucky, Lexington, KY 40506, USA

${ }^{10}$ Lead contact

*Correspondence: jjmcca2@uky.edu (J.J.M.), cpete4@uky.edu (C.A.P.)

https://doi.org/10.1016/j.isci. 2021.102372
} 
the early stage of MOV is sufficient to regulate ECM deposition and promote long-term hypertrophy in adult mice, independent from satellite cell fusion. Satellite cell depletion influences FAP fate progression toward fibrogenic and osteogenic transcriptional programs early during overload in vivo, concomitant with global- and FAP-specific upregulation of chemokine gene expression. Through delivery of miR-206 packaged in EVs, we identify a mechanism whereby satellite cells regulate fibrosis-associated Wnt-inducible signaling pathway protein 1 (Wisp1, also known as Ccn4) in FAPs during hypertrophy, the absence of which is associated with aberrant fibrogenic cell fate progression. We also provide evidence that satellite cell EV communication after the first few weeks of MOV is widespread but may be accentuated in endothelial cells. Fusion-independent satellite cell communication is a powerful stimulus to promote adult muscle growth, and we provide support for a model where initial reparative events trigger a cascade of cellular synchronization that enables long-term tissue homeostasis (Adler et al., 2020).

\section{RESULTS}

EV-mediated communication from myogenic to mononuclear cells following 14 days of mechanical overload

We report that there is a $275 \%$ increase in satellite cells concomitant with robust hypertrophy after 14 days of synergist ablation-induced MOV of the plantaris muscle (Kirby et al., 2016a; McCarthy et al., 2011). Using

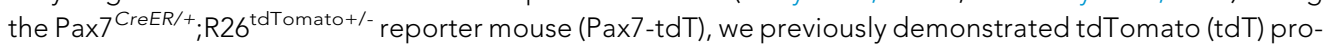
tein and mRNA in myogenic progenitor cell (MPC)-derived EVs, as well as $\mathrm{tdT}$ transfer to recipient cells via MPC EVs in vitro (Murach et al., 2020c); Video S1 is a high-magnification video showing tdT+ MPC EVs. Packaging of cytoplasmic localized reporter mRNA and/or protein in EVs is consistent with prior investigations (Aswad et al., 2014; Cossetti et al., 2014; Flaherty et al., 2019; Forterre et al., 2014; Gao et al., 2020; Kanada et al., 2015). Based on these results, we used the Pax7-tdT model to explore in vivo EV tracking from myogenic cells (satellite cells and/or myofibers) to mononuclear cells throughout muscle during hypertrophic growth in response to 14 days of MOV (Figure 1A).

We conducted FACS on cell suspensions from vehicle- and tamoxifen-treated 14-day MOV Pax7-tdT plantaris muscles, MOV tamoxifen-treated tdT parental strain muscles, and resting tamoxifen-treated Pax7-tdT muscles (flow cytometry gating for these experiments is in Figures S1A-S1D). As expected, satellite cells from vehicle-treated 14-day MOV Pax7-tdT and parental muscles were tdT negative (tdT-, Figure 1B for vehicle, parental shown in Figure S1A), and most satellite cells from tamoxifen-treated MOV Pax7-tdT muscles were brightly tdT fluorescent (Figure 1C, population 1). In muscles from MOV vehicletreated mice, non-satellite mononuclear cells (CD31 + endothelial cells, CD45 + immune cells, and/or Sca1+ mesenchymal cells) were tdT- (Figure 1D, population 2). This same population in muscles from tamoxifen-treated mice (Figure 1E, population 3) was expanded rightward, with some cells displaying clear tdT fluorescence (Figure 1E, population 4), and a second population that presumably contained a proportion of Sca1- FAPs/fibrogenic cells (Chapman et al., 2016) also appearing tdT+ (Figure 1E, population 5). Resting tamoxifen-treated Pax7-tdT muscle (collected from the forelimb and hindlimb) did not display appreciable tdT fluorescence other than in satellite cells, suggesting the appearance of tdT is mediated by activated satellite cells during MOV (Figure S1D). Based on the shift in tdT fluorescence observed via FACS in the tamoxifen condition, we posit that the appearance of tdT in non-satellite cells is due to spontaneous off-target Cre-mediated recombination because: 1) average fluorescence levels were appreciably lower than in satellite cells indicating the appearance of $t d T$ was not due to constitutive expression, 2) there was negligible fluorescence in 14 day $\mathrm{MOV} \mathrm{td} \mathrm{T}^{\mathrm{fl} / \mathrm{fl}}$ parental strain plantaris muscles nor resting tamoxifen-treated Pax7-tdT muscle. Within cell populations 1-5, quantitative reverse-transcription PCR (RT-qPCR) revealed the highest relative tdT mRNA levels in tamoxifen-treated satellite cells (indicative of constitutive viral promoter-driven expression following recombination), moderate $t d T$ mRNA in populations that had some tdT fluorescence, and low levels in all others (Figure 1F).

\section{Evidence that the appearance of $\mathrm{tdT}$ in non-satellite cells during MOV is not due to off-target recombination or technical artifact from tissue processing}

We evaluated recombination in genomic DNA of MPCs from vehicle- and tamoxifen-treated Pax7-tdT mice, as well as from the $t d \mathrm{~T}^{\mathrm{fl} / \mathrm{fl}}$ parental strain, and found that recombination of the stop cassette was only detectable in Pax7-tdT MPCs following tamoxifen treatment (Figures S2A and S2B). Analysis of DNA from pooled, non-satellite cell populations (CD31-/Ncam-, mesenchymal, fibrogenic, and immune cells), as well as CD31 + endothelial cells from tamoxifen-treated Pax7-tdT plantaris muscle following 14 days of MOV, showed the stop cassette was intact, indicating that fluorescence was not due to off-target 
A

$>3$ month old Pax7 tdTomato (Pax7-tdT) Veh $=$ Vehicle, Tam $=$ Tamoxifen

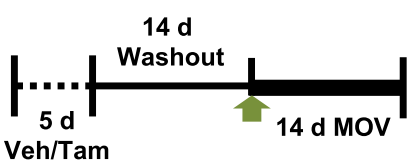

B

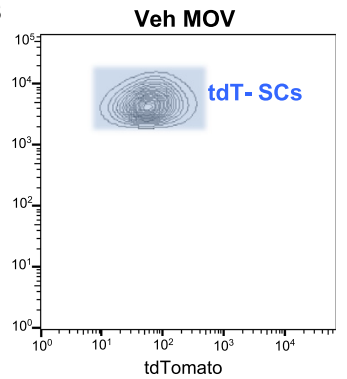

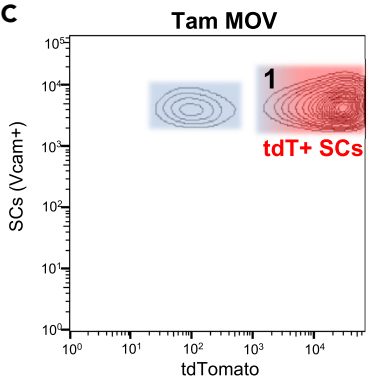

D

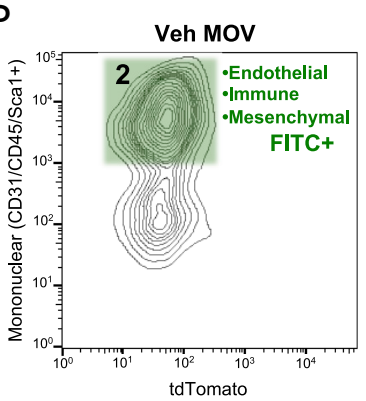

E

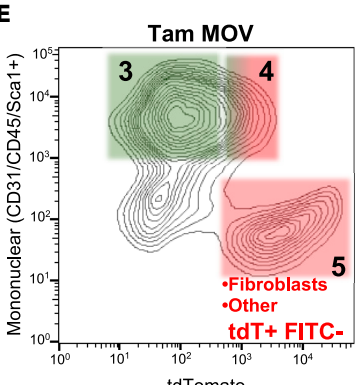

F

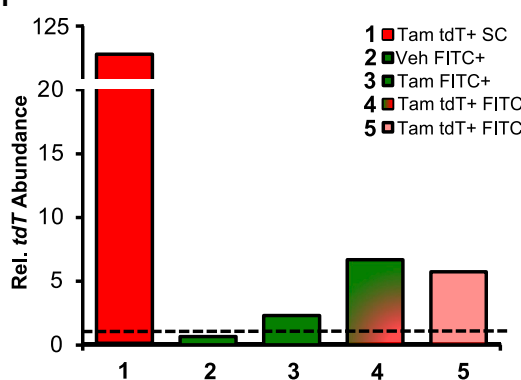

Figure 1. Delivery of tdTomato (tdT) from myogenic cells to mononuclear cells throughout skeletal muscle during 14 days of mechanical overload (MOV) of the plantaris

(A) Experimental design schematic showing vehicle (Veh) or tamoxifen (Tam) administration for 5 consecutive days ( 5 d), washout period, and 14 day MOV in Pax7-tdT mice; $n=3$ mice/6 plantaris muscles pooled for analysis captured at the same exposure and adjusted the same as the image in (B), scale bar, $20 \mu \mathrm{m}$.

(B) Flow cytometry plot illustrating Vcam + tdT- satellite cells (SCs) of Veh-treated Pax7-tdT MOV plantaris muscle; SCs were also negative for CD31 (endothelial cell marker), CD45 (immune cell marker), and Sca1 (mesenchymal stem cell marker).

(C) Flow cytometry plot illustrating Vcam+tdT+ SCs (population 1) in Tam-treated Pax7-tdT MOV plantaris muscle. SCs were also CD31-/CD45-/Sca1-

(D) Flow cytometry plot illustrating endothelial, immune, and mesenchymal stem cells in Veh-treated Pax7-tdT MOV muscle, all identified via FITC-conjugated antibodies (population 2).

(E) Flow cytometry plot illustrating endothelial, immune, and mesenchymal cells that were tdT- (population 3) and tdT+ (population 4) in Tam-treated Pax7-tdT MOV muscle, all identified via FITC-conjugated antibodies. Another cloud of tdT+ cells (population 5, most likely fibrogenic cells) was also identified.

(F) Quantitative real-time PCR for tdT mRNA abundance in populations 1-5. Dotted line represents tdT- cells sorted from the $t_{d} T^{f / f l}$ parental strain ( $n=3$ /group: Veh, Tam, and tdT parental mice, each pooled for sorting and RNA isolation), normalized to Gapdh and presented relative to parental strain cells using $2^{-\Delta \Delta C t}$.

See also Figure S1 and Video S1.

recombination (Figures S2A and S2B). To determine if the tdT protein detected in non-satellite cells might have been the result of tdT protein from lysed cells "sticking" to mononuclear cells in the single-cell suspension, we digested tamoxifen-treated 14-day MOV Pax7-tdT plantaris muscles and then used the Pax7tdT cell-free supernatant to digest wild-type (no tdT transgene in genome) MOV plantaris muscles (Figure 2A); primary cells from digested wild-type muscle were used as negative controls. FACS confirmed no tdT signal in controls (Figure 2B), tdT fluorescence in Pax7-tdT MOV muscle (Figure 2C), and minimal fluorescent labeling from "sticky" tdT protein and/or cellular debris as a consequence of the digestion process (Figure 2D). Furthermore, isolation of Vcam-/CD31- and Vcam-/CD31 + cells from wild-type muscles followed by qPCR showed that exposure to cell-free supernatant from overloaded wild-type muscles ("mixed" in Figure 2E) did not account for tdT transcript levels observed in those cell populations from tamoxifen-treated Pax7-tdT MOV muscles (Figure 2E). The results of these experiments collectively indicated that neither off-target recombination nor cellular disruption and non-specific labeling/uptake can explain the magnitude of the appearance of tdT protein and transcript in non-satellite cells of tamoxifen-treated MOV Pax7-tdT muscle. Our results are also consistent with similar experiments conducted in thymus tissue using two comparable inducible cell-specific reporter Cre models after observations of fluorescence transfer between cells in vivo (Wang et al., 2016). 


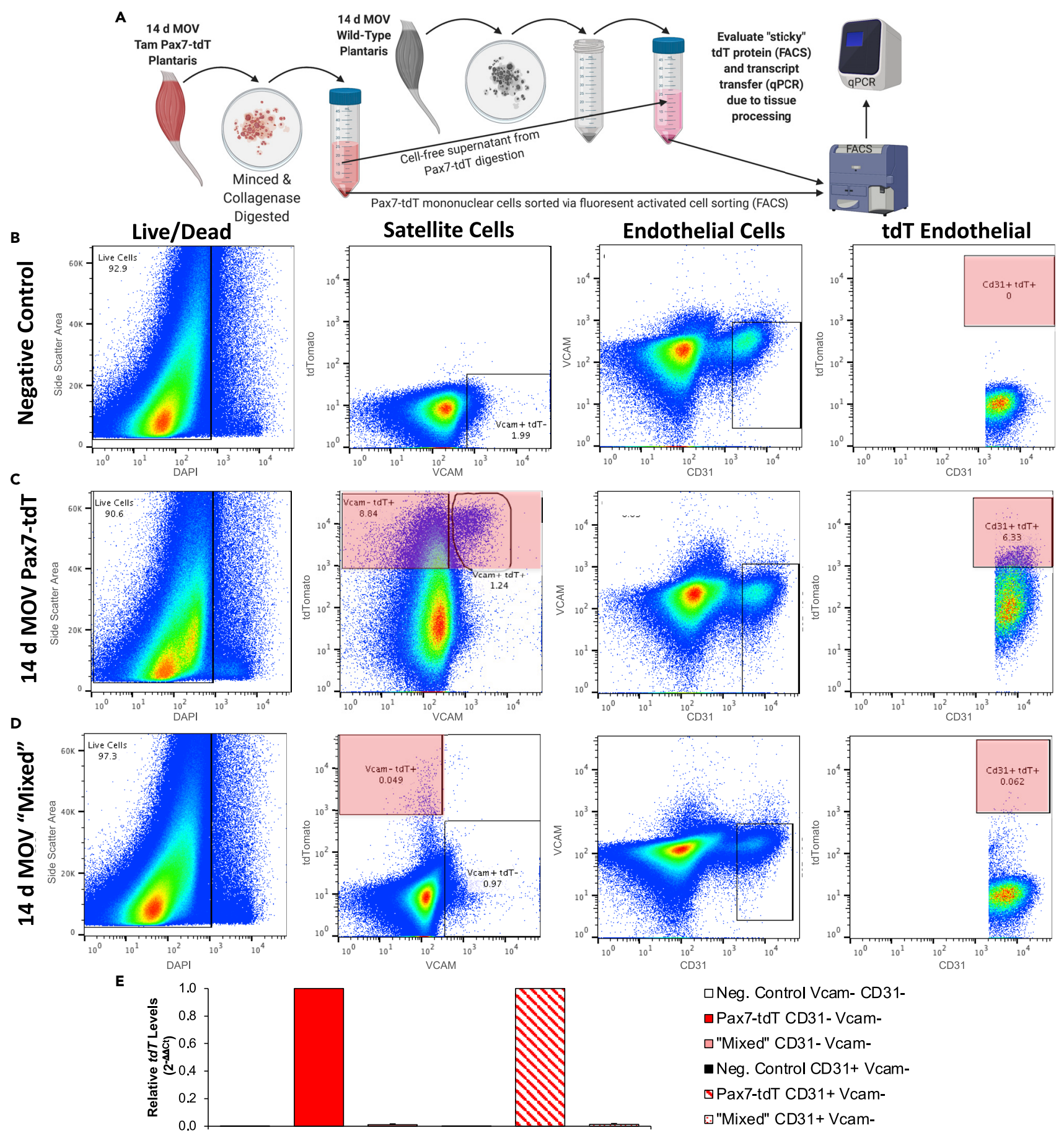

Figure 2. Presence of tdTomato (tdT) protein and mRNA in non-satellite cells (SCs) during mechanical overload (MOV) is not attributable to technical artifact from tissue processing

(A) Experimental design illustrating how cell-free supernatant from digested Tam-treated 14-day MOV Pax7-tdT muscles ( $\mathrm{n}=2$ mice/4 plantaris) was used to digest wild-type (no tdT transgene in genome) $14 \mathrm{~d}$ MOV muscles ("mixed", $n=3$ mice/2 separate pools of 3 plantaris, processed as technical replicates), followed by FACS isolation of different populations for downstream analyses.

(B) Flow cytometry plots from muscle digest of unperturbed wild-type muscle (triceps and quadriceps), used as a negative control for tdT fluorescence; forward and side scatter area gating not shown.

(C) Flow cytometry plots from Tam-treated 14-day MOV Pax7-tdT muscles, confirming the appearance of tdT in satellite and non-satellite cell (endothelial and non-endothelial) populations; forward and side scatter area gating not shown. 
Figure 2. Continued

(D) Flow cytometry plots from MOV wild-type control plantaris muscle digested with the cell-free supernatant from Tam-treated 14-day MOV Pax7-tdT plantaris muscle ("mixed"); forward and side scatter area gating not shown.

(E) tdT mRNA levels in Vcam-/CD31- mononuclear cells and CD31+/Vcam-endothelial cells in resting control, Tam-treated 14-day MOV Pax7-tdT, and 14day MOV wild-type control muscle "mixed" with cell-free supernatant from the Pax7-tdT muscle digestion, normalized to 18S rRNA and presented relative to the respective cell type in the Pax7-tdT condition using $2^{-\Delta \Delta C t}$.

See also Figures S2 and S3.

\section{scRNA-seq reveals the identity of tdT+ mononuclear cells after 14 days of MOV}

To further interrogate the identity of tdT + mononuclear cells in muscle after 14 days of MOV, we conducted FACS and isolated all cells with tdT fluorescence in tamoxifen-treated 14-day MOV Pax7-tdT muscles (Figures $3 \mathrm{~A}$ and $3 \mathrm{~B}$ ) and conducted droplet-based 10X Genomics Chromium scRNA-seq. The scRNA-seq preparation was enriched for satellite cells, as would be expected, but a variety of cell types according to global transcriptional profiles were also identified via scRNA-seq, including fibrogenic cells (fibroblasts and FAPs), immune cells/macrophages, and endothelial cells (Figure 3C). These data suggest that by 14 days of MOV, myogenic cells communicate with the major mononuclear cell populations throughout the muscle. Myonuclei also appeared in the preparation, identified by myosin heavy chain transcripts, consistent with recent reports (De Micheli et al., 2020; Oprescu et al., 2020). To interrogate tdT message within the scRNA-seq data set, we created a custom transcriptome where the $t d T$ transgene (Madisen et al., 2010) was included in the mouse $\mathrm{mm} 10$ annotated transcriptome. At the transcript level, the highest $t d T$ levels were in satellite cells and what were likely satellite cell-derived myonuclei (top of "myonuclei" cluster, Figure 3C). Myonuclei with very high $t d T$ expression $\left(\log _{2} t d T>3\right.$ ) had elevated levels of cell cycle regulatory genes Cdkn1a and Btg2, as well as myosin light chain 1 embryonic (Myl4) (false discovery rate [FDR] adjusted $p<0.05$ ) and developmental myosins (Myh3 and Myh8), suggesting nascent myonuclei as a result of satellite cell fusion.

We were uncertain whether transfer of tdT mRNA via satellite cell EVs to non-myogenic cells would be detectable using scRNA-seq given the relatively low sequencing depth obtained with this technique, as well as the potentially large amount of EV communication that would be required to occur. Recent evidence suggests that EV material transfer from wild-type cells of one lineage in vivo can be sufficient to restore the protein levels of a knocked-out gene in a distinct cell type (Crewe et al., 2018). The findings of Crewe et al. illustrate the robust and under-appreciated potential of EV-mediated cargo transfer, which made the detection of $t d T$ transcript on a cell-by-cell basis in non-satellite cell populations via scRNA-seq seem worthwhile to explore. To first determine background levels of $t d T$ mRNA, we conducted scRNA-seq on cells from tamoxifen-treated 14-day MOV tdT $\mathrm{T}^{\mathrm{fl} / \mathrm{fl}}$ parental strain plantaris muscles. Despite the absence of detectable fluorescence via FACS (see Figure S1), low levels of full-length $t d T$ transcript were detected in some mononuclear cells via scRNA-seq, indicating occasional readthrough of the stop cassette (3x SV40 poly(A) signal) in the R26R-tdT $T^{f / f l}$ mouse (green box, Figure S3A). As expected, we also were able to detect abundant truncated $t d T$ transcript (a short polyadenylated message generated by transcription up to the stop sequence, Figure S3A) providing evidence that the stop cassette was intact (Madisen et al., 2010) (Figure S3A). To account for the low level tdT expression, we generated a null distribution using the ratio of $t d T$ full length to $t d T$ truncated for each cell in the MOV tdT parental scRNA-seq data, where any full-length $t d T$ transcript would be expected to be a consequence of readthrough (or perhaps spurious recombination). Using the non-parametric prediction interval and the probability for each sequenced cell, we determined whether its ratio was functionally indistinguishable from the null distribution of background readthrough and then corrected for multiple comparisons using FDR. With these criteria, very few cells in the parental MOV experiment had tdT expression above background levels (Figure S3B). Conversely, many cells had full-length $t d T$ expression above the readthrough background levels in the Pax7-tdT MOV experiment (with varying degrees of confidence according to FDR, see Figure S3B). Furthermore, truncated tdT transcript levels can be used as a second method to assess off-target recombination, where high levels relative to a control (e.g. recombined satellite cells in tamoxifen-treated Pax7-tdT mice) indicate that the stop cassette effectively prevented constitutive expression of the downstream $t d T$ coding sequence. Truncated transcript was virtually undetectable in Pax7+ and MyoD + cells (satellite cells) in the 14-day MOV Pax7-tdT experiment but was expressed at high levels in all other cell populations, providing further evidence of minimal off-target recombination in non-myogenic cells (Figures S3C and S3D).

We asked whether non-myogenic cells containing higher versus lower amounts of tdT mRNA in the FACS isolated tdT+ cells could be discriminated in the scRNA-seq data, suggesting functional consequences to potentially higher levels of EV-based communication in vivo. Besides satellite cells and myonuclei (Figures 
A

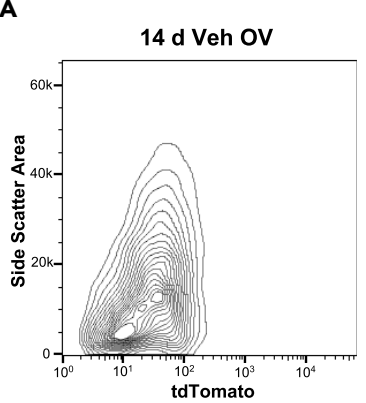

D

tdT Low $(n=178)$

tdT High $(n=32)$

Endothelial Cells

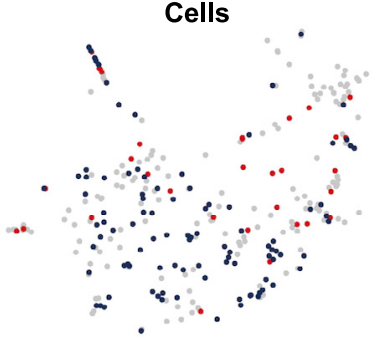

B $14 \mathrm{~d}$ Tam ov C

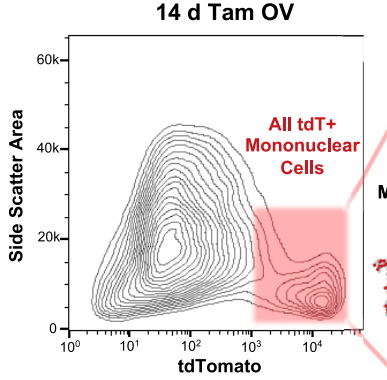

scRNAseq: $t d T$ Abundance ( $\log 2>2$ )

Fibroblasts/FAPs
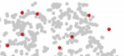

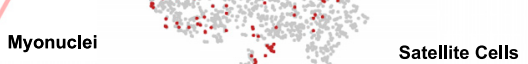

Myonuclei Satellite Cells

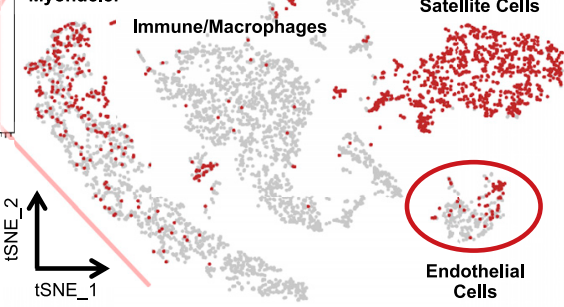

E

Top Unique Down-Regulated Pathways

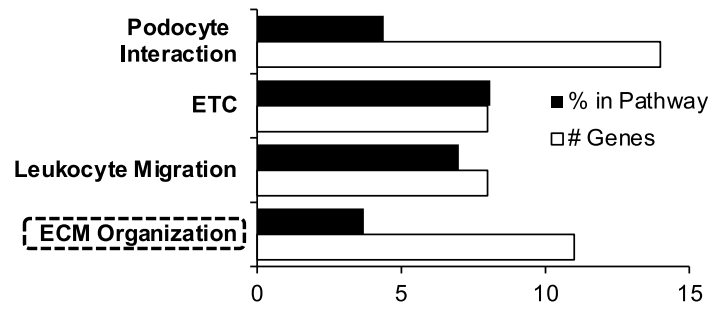

Figure 3. Single-cell RNA sequencing (scRNA-seq) analysis of extracellular vesicle (EV)-mediated communication from myogenic cells during 14 days of mechanical overload (MOV)

(A) Flow cytometry plot illustrating a lack of tdTomato+ (tdT+) cells in Veh-treated 14 d MOV Pax7-tdT plantaris muscle ( $n=1$ mouse/2 plantaris muscles, used for establishing background fluorescence).

(B) Flow cytometry plot illustrating tdT+ cells in Tam-treated $14 \mathrm{~d}$ MOV plantaris muscle ( $\mathrm{n}=4$ mice/8 plantaris muscles pooled for analysis).

(C) t-distributed stochastic neighbor embedding atlas representing appreciable (log2>2) tdT transcript detected in the Tam-treated Pax7-tdT MOV sample via scRNA-seq.

(D) Endothelial cell cluster from t-distributed stochastic neighbor embedding (t-SNE) atlas, illustrating tdT-negative cells ( Log $_{2} t d T$, tdT 5', Pax7, Myod, and Myog = 0, $\mathrm{n}=99$ blue cells) and tdT high cells (Log 2 tdT > 2, tdT5', Pax7, Myod, and Myog $=0, \mathrm{n}=32$ red cells).

(E) Top unique downregulated pathways from KEGG, WikiPathways, and Reactome analyses using the top 100 differentially expressed genes in $t d T$ high vs $t d T$-negative endothelial cells from the tdT+ FACS isolated cluster, organized in descending order according to $p$ value (all were $p<0.05$ ). ETC, electron transport chain, ECM, extracellular matrix.

See also Figure S4.

3C), we noticed that a subset of endothelial cells had the highest absolute levels of full-length $t d T$ transcript (Figure 3D). Although absolute endothelial cell numbers were small, we compared the transcriptional profiles of $t d T$ high endothelial cells ( $\log _{2} t d T>2$, not expressing Pax7, MyoD, and MyoG, and residing within the CD31/Pecam1-enriched endothelial cluster) to endothelial cells lacking $t d T$. Global pathway analysis of the top 100 genes with lower expression (using absolute as well as Log2 differences) revealed ECM organization as one of the top unique downregulated processes in tdT-high endothelial cells (Figures $3 E$ and S4A). Furthermore, the ECM-remodeling genes Timp4 and Comp were trending to be lower in tdT-high endothelial cells (adj. $p<0.10$ ). Some genes were lower in tdT-high endothelial cells as well, suggesting myogenic cells may influence angiogenic-related processes via EV communication (Figure S4B). In silico analysis using miRNAs abundant in MPC EVs (Murach et al., 2020c) predicted miRNA interactions consistent with changes in target gene expression in endothelial cells (Figure S4C). While this preliminary analysis was instructive, the presence of high $t d T$-expressing myonuclei after 14 days of MOV prevents us from drawing firm conclusions regarding the definitive source of $t d T$-containing EVs in vivo (i.e. satellite cells versus muscle fiber that experienced satellite cell fusion). 
Satellite cell communication to mononuclear cells during the first $96 \mathrm{hr}$ of MOV affects the ECM and chemokine gene expression

We performed a similar scRNA-seq experiment as above but at an earlier time point, prior to the fusion of satellite cells to myofibers, to determine the precise source of tdT in non-satellite cells after MOV in Pax7tdT muscle. After subjecting tamoxifen-treated Pax7-tdT mice to MOV for $96 \mathrm{hr}$, we harvested the muscle, removed Vcam + cells via FACS, and then conducted scRNA-seq (see Figure S5 for flow cytometry gating). We did not observe a prevalent population of $t d T+$ non-satellite cells via FACS (as in the 14-d MOV experiments), and utilizing the aforementioned full length to truncated $t d T$ transcript ratio, background correction did not reveal bona fide tdT mRNA-containing cells in the preparation. It is conceivable that $96 \mathrm{hr}$ of MOV was not a long enough duration for satellite cells to proliferate sufficiently and transfer enough tdT mRNA to mononuclear cells to be detectable by scRNA-seq.

Given the technical challenges of blocking cell type-specific EV release (Gandham et al., 2020; Vechetti et al., 2020), and consistent with our previously published approach (Murach et al., 2020c), we employed our inducible in vivo satellite cell depletion model, the Pax7-DTA mouse (McCarthy et al., 2011; Murach et al., 2017), to gain insight into how satellite cells communicate throughout the muscle. We subjected tamoxifen-treated Pax7-DTA mice to MOV for $96 \mathrm{hr}$ (Figure 4A), removed Vcam+ cells, conducted scRNA-seq, and then compared these results to the $96 \mathrm{hr} \mathrm{MOV}$ satellite cell replete experiment above (Figure $4 B$ ). In context with our prior work showing a secretory effect of satellite cells on fibrogenic cells during overload (Fry et al., 2014a, 2017), we first focused on differences in FAPs between satellite cell deplete and replete muscle. In the Pdgfr $\alpha$-enriched FAP cluster, Col1a1 (the most differentially expressed gene in absolute terms) was $62 \%$ higher in the absence of satellite cells (adjusted $p<0.10$, Figure $4 \mathrm{C}$ ). Other highly expressed ECM genes such as Col1a2 (42\% higher), Timp1 (93\% higher, adj. p < 0.05), and Tnc (83\% higher, adj. $p=0.07$ ) were also higher in the absence of satellite cells during MOV (Figure 4C). Furthermore, FAPs from satellite cell-depleted muscle after $96 \mathrm{hr}$ of MOV had higher Ccl2 (90\%, adj. p < 0.05), Ccl7 (98\%, adj. $\mathrm{p}<0.05)$, and Cxcl5 (453\%, adj. p < 0.05) (Figure 4D); this is noteworthy since upregulation of these specific immune markers distinguishes activated FAPs within $12 \mathrm{hr}$ of regenerative injury (Oprescu et al., 2020). Satellite cells also affected immune gene expression outside of fibrogenic cells. Abundant chemokines such as $\mathrm{Ccl} 2(\mathrm{p}=0.12), \mathrm{Ccl} 7$, and $\mathrm{Cxcl1}$ were higher in mononuclear cells throughout the muscle in the absence of satellite cells (adj. $p<0.05$, Figure 4E). Given the potential endothelial cell-specific effect of myogenic cell EV communication observed at 14 days of MOV, we interrogated endothelial cells at $96 \mathrm{hr}$ and observed a similar induction in chemokine gene expression in the absence of satellite cells, which included higher $\mathrm{Ccl} 2$, Ccl7, and Cxcl1 (adj. $p<0.05$, Figure 4F).

Satellite cell communication during the first $96 \mathrm{hr}$ of MOV involves an EV-mediated miR-206/ Wisp 1 axis

Wisp1 is a secreted matricellular protein that was recently shown to be enriched in FAPs (Lukjanenko et al., 2019; Oprescu et al., 2020) and is generally associated with fibrogenic cell proliferation and fibrosis (Berschneider et al., 2014; Berschneider and Königshoff, 2011; Colston et al., 2007; Ono et al., 2018; Venkatachalam et al., 2009). Immune gene-enriched FAPs transition to ECM gene-enriched Wisp1+ FAPs between 3.5 and 5 days after injury, indicative of cell state progression toward a more fibrogenic phenotype (Oprescu et al., 2020). FAPs in the absence of satellite cells during MOV had higher Wisp 1 (93\%, adj. $p<0.05)$, which points to accelerated progression of a fibrogenic program in FAPs when satellite cells are absent; this was especially apparent in the FAP cluster most enriched with Pdgfr (Figure 5A). In MPC EVs, miR-206 is the most abundant miRNA (Fry et al., 2017; Murach et al., 2020c), and several bioinformatic analyses in the context of cancer (Seifi-Alan et al., 2018), as well as murine RNA hybrid analysis ( $\Delta \mathrm{G}-21.7$ for binding) (Krüger and Rehmsmeier, 2006), indicated that Wisp1 could be targeted by miR-206. We reasoned that EV delivery of miR-206 could explain lower Wisp1 in FAPs during MOV in the presence of satellite cells in our scRNA-seq experiment. Incubation of primary fibrogenic cells (equivalent to FAPs) (Contreras et al., 2019) with MPC-conditioned media, co-culture with MPCs, and treatment with MPC EVs (Figure 5B) all lowered Wisp 1 in fibrogenic cells ( $p<0.05$, Figure $5 C$ ). Transfection of miR-206 into fibrogenic cells similarly reduced Wisp1 ( $p<0.05$, Figure $5 C$ ). Other miRNAs abundant in MPC EVs (Murach et al., 2020c), such as miR-92a (Berschneider et al., 2014), may also contribute to satellite cell-mediated repression of Wisp1 in FAPs during MOV. Nevertheless, in context with our prior work showing MPC EV-mediated miR-206 repression of Rrbp1 in fibrogenic cells (Fry et al., 2017), these in vitro experiments provide evidence for EV delivery of miR-206 as an explanation for Wisp1 repression in FAPs by satellite cells. 
A

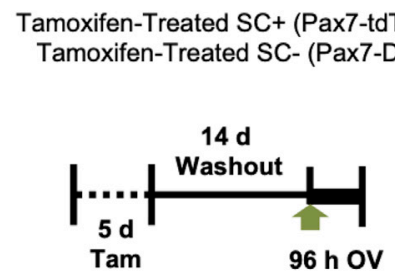

Tamoxifen-Treated SC+ (Pax7-tdT) and amoxifen-Treated SC- (Pax7-DTA) $96 \mathrm{~h} \mathrm{OV}$

B

Pdgfra neg.
fibrogenic

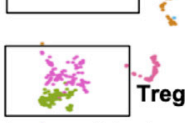

SC+

1
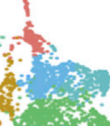

Macrophages

Myeloid

Pdgra-enriched

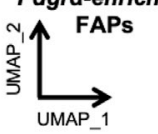

Myonuclei

Neutrophils

Pdgra-enriched
FAPs

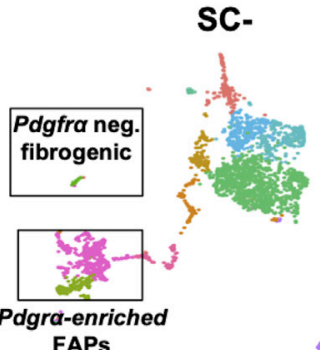

Endothelial

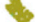

Pdgfra-enriched FAPs

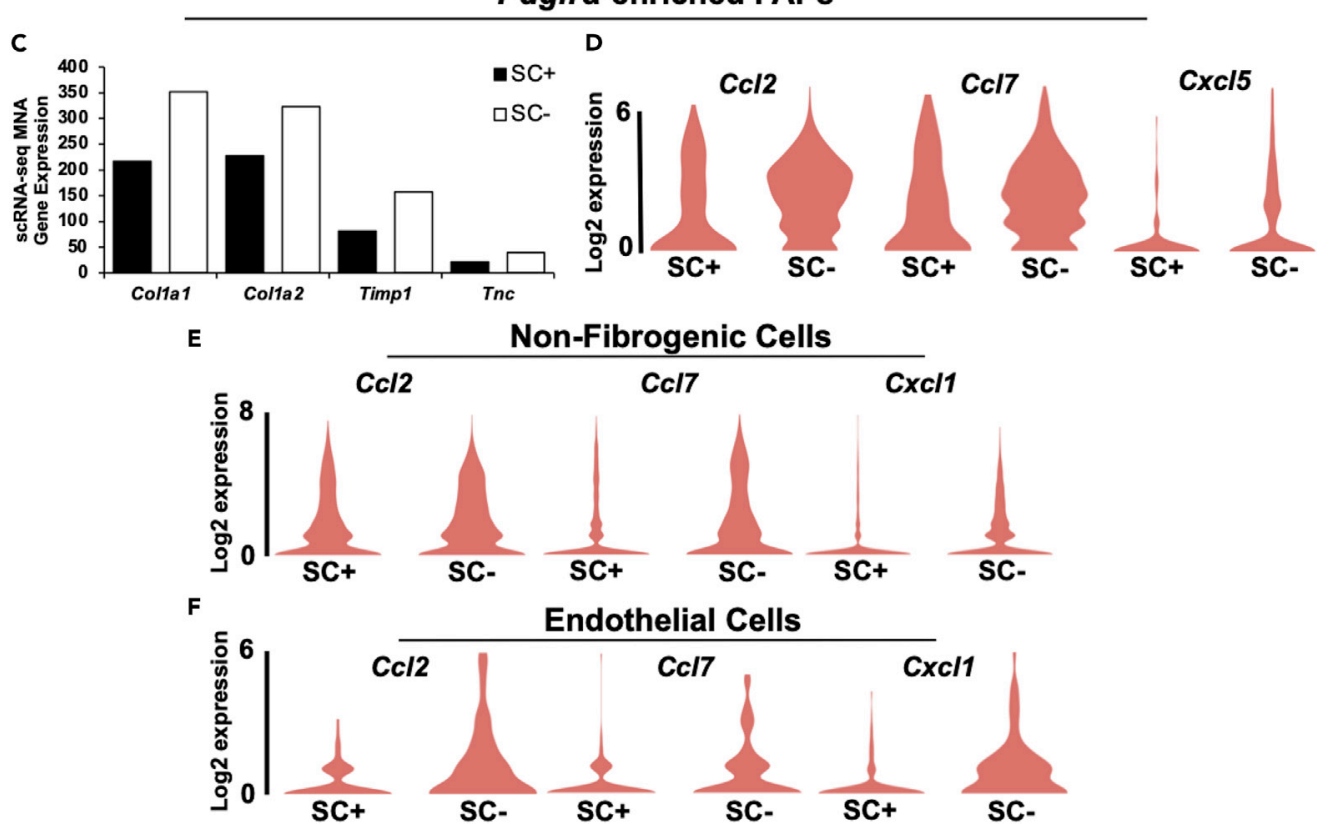

Figure 4. scRNA-seq after $96 \mathrm{hr}$ of mechanical overload (MOV) in the presence (SC+) and absence (SC-) of satellite cells

(A) Experimental design schematic demonstrating the Tam treatment strategy, washout period, and $96 \mathrm{hr}$ synergist ablation-induced MOV in Pax7-tdT (SC+) and Pax7-DTA (SC-) mice, $n=4$ mice/8 pooled plantaris per group.

(B) Uniform manifold approximation and projection (UMAP) atlas of scRNA-seq data in 96 hr MOV SC+ and SC-plantaris muscle. FAP, fibro/adipogenic progenitor cell, Treg, T-regulatory cell.

(C) Expression of extracellular matrix-related genes in Pdgfr $\alpha$-enriched FAPs during MOV in the presence (SC+) and absence (SC-) of SCs.

(D-F) Expression of chemokine genes in the presence or absence of SCs in (D) Pdgfr $\alpha$-enriched FAP clusters, (E) nonfibrogenic cells, and (F) endothelial cells. MNA, median normalized average.

See also Figure S5.

Trajectory inference analyses revealed altered cell state progression in the absence of satellite cells during the first $96 \mathrm{hr}$ of MOV

We sought to gather more detailed information on how satellite cells affect mononuclear cell fate progression during the early phase of MOV. We therefore conducted RNA velocity to model cell differentiation trajectories over pseudotime (Bergen et al., 2020; La Manno et al., 2018) and extended the results with the orthogonal method partition-based graph abstraction (which combines clustering with pseudotemporal ordering for trajectory analysis) (Wolf et al., 2019). These analyses involve the relative abundance of spliced and un-spliced transcripts to predict cell fate trajectories (La Manno et al., 2018). Following satellite cell depletion, three cell populations were statistically over-represented after $96 \mathrm{hr}$ of MOV in the spliced read data set (Figure 6A). In addition to Pdgfr $\alpha$-expressing FAPs, a cluster of $P$ dgfr $\alpha$-negative cells enriched 
A

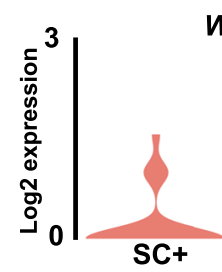

Wisp1

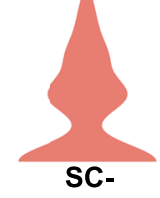

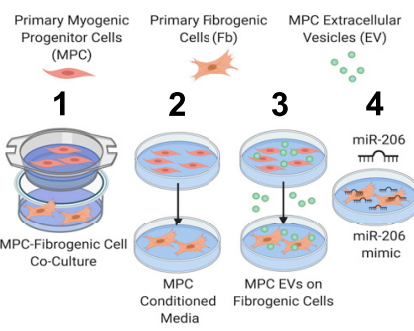

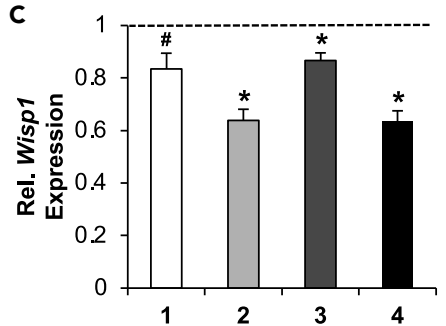

Figure 5. Wisp1 in primary fibrogenic cells (Fbs) is regulated by primary myogenic progenitor cells (MPCs) via an EV-mediated miR-206 delivery mechanism

(A) Wisp1 levels in Pdgfr $\alpha$-high FAPs after $96 \mathrm{hr}$ of MOV in the presence and absence of satellite cells (SCs), measured by scRNA-seq

(B) Experimental design schematic illustrating (1) MPC-Fb co-culture, (2) MPC conditioned media incubated with Fbs, (3) MPC EVs incubated with Fbs, and (4) miR-206 mimic or scrambled oligonucleotide transfected into Fbs for 24 hr. (C) Wisp1 gene expression in Fbs in conditions 1-4, relative to their respective control condition (dotted line), normalized to the geomean of $18 \mathrm{~S}$ rRNA and Gapdh and presented as $2^{-\Delta \Delta C t}$. ${ }^{*} p=0.05,{ }^{\star} p<0.05$, data are presented as mean \pm SEM.

with ECM genes was over-represented in the absence of satellite cells (Figure 6A and see Figure 4B). Since Pdgfr $\alpha$ expression typically defines FAPs (Joe et al., 2010; Uezumi et al., 2010; Wosczyna et al., 2019), this unique cluster either represented fibroblasts (Chapman et al., 2016) or transitional-state FAPs (Oprescu et al., 2020) and demonstrated high expression of ECM-related genes such as collagens, Lox, and Sparc. We observed that some FAPs were indeed predicted to be transitioning toward Pdgfr $\alpha$-negative fibrogenic cells with satellite cell depletion (Figures 6B and 6C).

Another cell population, seemingly with a continuous trajectory from the FAP cluster and enriched with cell cycle markers such as Pclaf and Top2a, was also abundant in the absence of satellite cells (Figures 6A and 6B). This cluster featured high expression of Acp5 and Ctsk, which are characteristic of osteogenic cells (Hayman et al., 1996; Inaoka et al., 1995; Minkin, 1982; Tezuka et al., 1994), but undetectable Pdgfr (Figure 6D). In addition to being fibrogenic/adipogenic, FAPs also have osteogenic potential (Lees-Shepard et al., 2018; Wosczyna et al., 2012), especially in an altered muscle inflammatory environment (Eisner et al., 2020). We hypothesize that dysregulation of inflammatory-related signaling throughout the muscle in the absence of satellite cells may have augmented the likelihood of osteogenic FAP appearance during MOV, contributing to the transition we observe in our trajectory analyses. Furthermore, Wisp1 is well characterized as a crucial mediator of osteogenic cell fate progression (French et al., 2004; Inkson et al., 2008, 2009; Maeda et al., 2015; Ono et al., 2011) and is significantly elevated in Pdgfr $\alpha$-expressing fibrogenic FAPs in the absence of satellite cells (see above). Also worth noting is that miR-206 (which inhibits Wisp1) is known to suppress osteogenic cell fate progression (Inose et al., 2009). Osteogenic FAPs are cleared by macrophages after injury which prevents muscle ossification (Eisner et al., 2020), but understanding how satellite cells affect this process during MOV warrants further investigation.

\section{The presence of satellite cells for the first $96 \mathrm{hr}$ of MOV is sufficient to support long-term hypertrophy, independent from myonuclear accretion}

Long-term hypertrophy is blunted by the complete absence of satellite cells (Englund et al. 2020a, 2020b; Fry et al. 2014a, 2017). To test whether the presence of satellite cell communication early during MOV is sufficient to support long-term hypertrophy, we subjected Pax7-DTA mice to 8 weeks of MOV but administered vehicle $(\mathrm{SC}+$ ) or tamoxifen (SC-) beginning at $96 \mathrm{hr}$ after synergist ablation surgery (96hr, Figure $7 \mathrm{~A}$ ); sham-operated mice served as controls. Satellite cells were effectively reduced with tamoxifen treatment (Figure 7B, p < 0.05), and myonuclear accretion was prevented in SC $96 \mathrm{hr}$ muscle after 8 weeks of MOV (Figure $7 C, p<0.05$ ). The accumulation of muscle mass (Figure 7D), large muscle fibers (rightward shift, Figures 7E and 7F), fiber number on cross section (Figure 7G), and ECM content (Figures 7H and 7I) were comparable between SC+ and SC- muscles. While wet weight was not different between groups, the proportion of very large fibers $\left(>2800 \mu \mathrm{m}^{2}\right.$ ) was numerically lower in the absence of satellite cells (Figure 7F), raising the possibility that an upper limit to the "myonuclear domain" was approached, affecting further myofiber growth. Collectively, these findings complement our previous long-term MOV data in which satellite cells were depleted after 7 days (Fry et al., 2017), but the complete prevention of myonuclear 
A

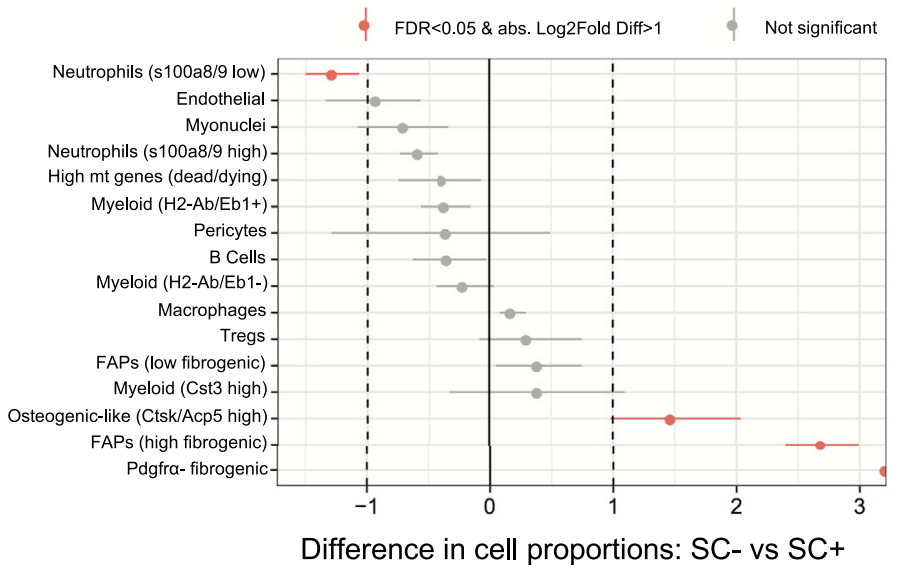

B

$\underline{\mathrm{SC}+}$

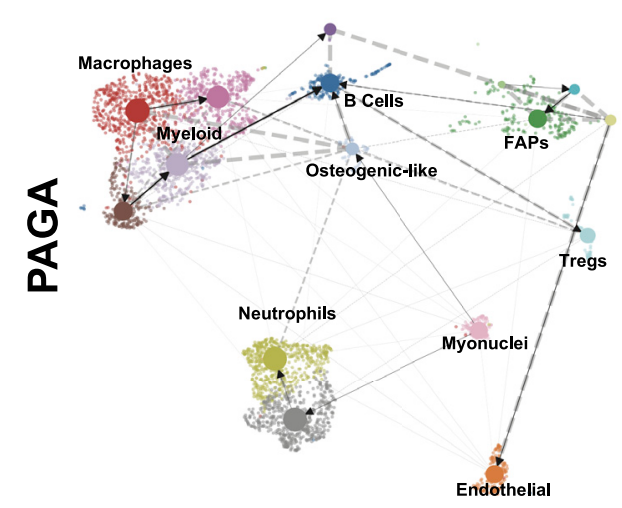

C

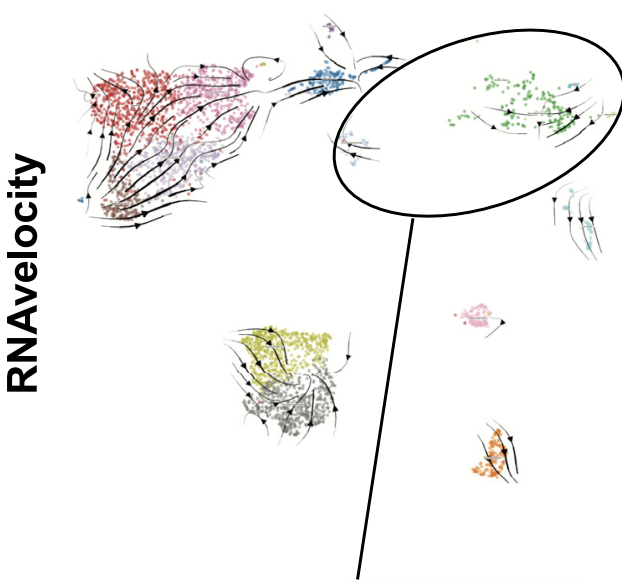

Osteogenic-like

告, $a^{2} z^{2}+\ldots$

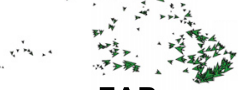

FAPs
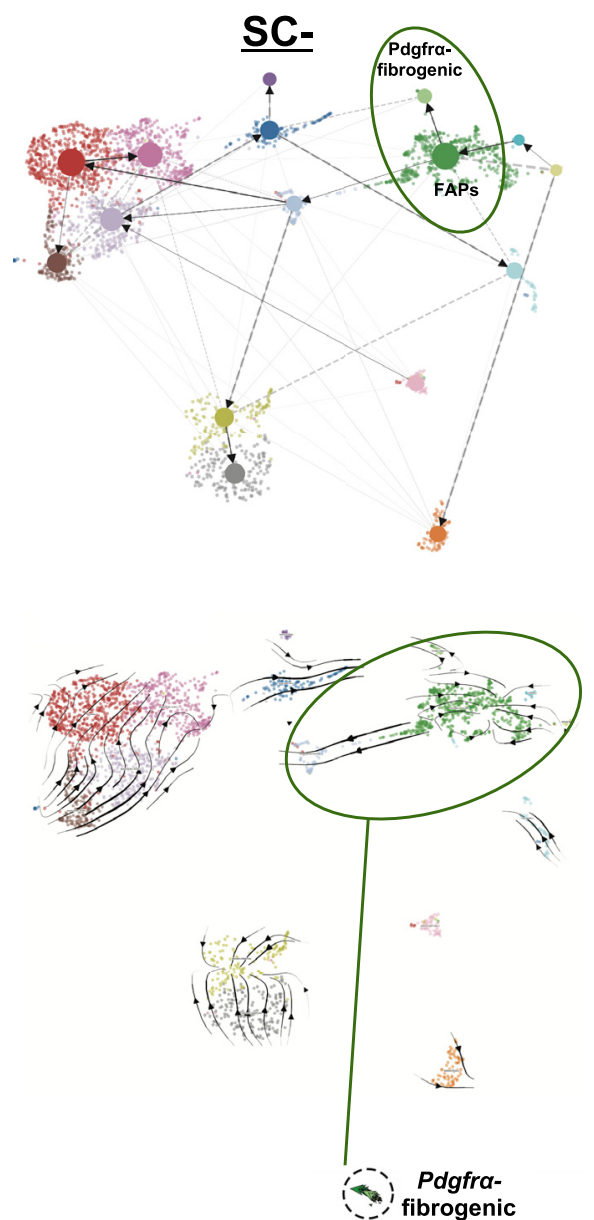

Osteogenic-like

Acp5 and Ctsk high Pclaf and Top2a high

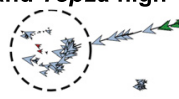


Figure 6. scRNA-seq trajectory inference analyses after $96 \mathrm{hr}$ of mechanical overload (MOV) in the presence and absence of satellite cells (SCs)

(A) Statistical differences in Log 2 cell proportions in scRNA-seq experiments between $96 \mathrm{hr}$ of $\mathrm{MOV}$ in SC+ and SCplantaris muscles.

(B) Partition-based graph abstraction (PAGA) analysis illustrates the appearance of a Pdgfr $\alpha$-negative fibrogenic cell population in the absence of satellite cells.

(C) RNA velocity analysis shows FAPs predicted to be transitioning toward two distinct cell populations in the absence of satellite cells.

(D) Magnified view of the FAP cluster from RNA velocity showing a Pdgfr $\alpha$-negative fibrogenic cell population in close proximity to FAPs, as well as an osteogenic-like cell population predicted to arise from FAPs preferentially in the absence of SCs during MOV.

accretion with satellite cell depletion at $96 \mathrm{hr}$ observed here suggests that satellite cell secretory function early during MOV is permissive for long-term muscle hypertrophy in adult fast-twitch plantaris muscles.

\section{DISCUSSION}

Using the Pax7-tdT reporter mouse and scRNA-seq, we show that myogenic cells (satellite cells and/or myofibers) are potentially communicating with endothelial cells in vivo via EVs following 14 days of MOV, which is related to an altered transcriptional profile in target cells. EV-mediated communication broadens the scope of myogenic cell-to-endothelial cell secretory signaling described in other models (Christov et al., 2007; Nie et al., 2019; Rhoads et al., 2009; Verma et al., 2018). After 96 hr of MOV, communication specifically from satellite cells is most evident in fibrogenic cells. The absence of satellite cells was associated with transcriptionally distinct fibrogenic populations, and this could be related to EV-mediated delivery of miR-206 that represses pro-fibrogenic Wisp1 in FAPs. Worth noting is that the removal of Vcam + cells in our experiments, while done in both conditions, may have excluded a recently described Vcam+ FAP population that emerges during regeneration and disease (Malecova et al., 2018). Nevertheless, our satellite cell deplete data are consistent with the nearly two-fold induction of proliferating fibrogenic cells observed early after degenerative injury in the absence of satellite cells (Murphy et al., 2011), as well as the amplified accrual of ECM-generating cells that manifest after a longer period without satellite cells following MOV or injury (Fry et al., 2014a, 2017; Murphy et al., 2011). Our findings also comport with activated satellite cell EV miRNA cargo being principally targeted toward ECM deposition and remodeling processes (Fry et al., 2017; Murach et al., 2020c). The predicted appearance of osteogenic-like (seemingly FAP-derived) cells after $96 \mathrm{hr}$ of MOV, which was accentuated in the absence of satellite cells, further points to robust satellite cell regulation of FAPs in vivo. When satellite cells were only present for the first $96 \mathrm{hr}$ of MOV, successful hypertrophy after 8 weeks illustrates the powerful secretory function of these cells in supporting adult muscle hypertrophy, independent from myonuclear accretion (Murach et al., 2018a, 2018b).

Numerous investigations demonstrate reporter transfer from one cell type to another in vivo (Cossetti et al., 2014; Murach et al., 2020c; Ortin-Martinez et al., 2017; Pearson et al., 2016; Wang et al., 2016) that is likely mediated by EVs, which are shown to package and transfer genetic reporters (Aswad et al., 2014; Cossetti et al., 2014; Flaherty et al., 2019; Forterre et al., 2014; Gao et al., 2020; Kanada et al., 2015; Murach et al., 2020c). The specificity of recombination in inducible Cre-driven reporters is well accepted, but when "leaky" recombination has been observed, it is generally restricted to the lineage being traced (Álvarez-Aznar et al., 2020; Chappell-Maor et al., 2019; Stifter and Greter, 2020; Van Hove et al., 2020). Recombination in the Pax7-tdT model is well accepted as specific to satellite cells (Cho and Doles, 2017; Keefe et al., 2015; Matthews et al., 2016; Pawlikowski et al., 2015; Summers et al., 2017), so our control experiments, taken together with the literature, collectively suggest that EV delivery of cytoplasmic-localized reporter protein and/or transcript may explain, at least in part, the appearance of tdT in non-satellite cell populations during MOV. We cannot rule out that muscle fibers, in addition to satellite cells, were communicating throughout muscle in our model due to satellite cell fusion by 14 days (evidenced by tdT expression), but this communication appeared preferential toward endothelial cells, which satellite cells are known to communicate with (Verma et al., 2018). More sensitive EV-tracking tools, as well as advances in scRNA-seq, may be required to better characterize satellite cell EV-specific communication throughout the muscle very early during hypertrophy. Future investigations will aim to address these limitations, but the current data collectively suggest that satellite cell EV communication is directed toward fibrogenic cells during the early stage of hypertrophy and may have greater influence on endothelial cells later during growth. 
A

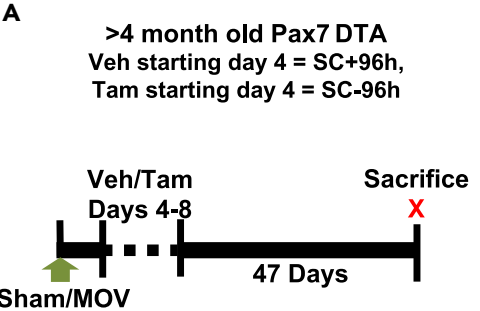

Sham/MOV

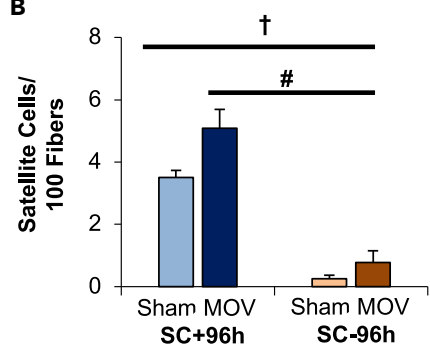

C

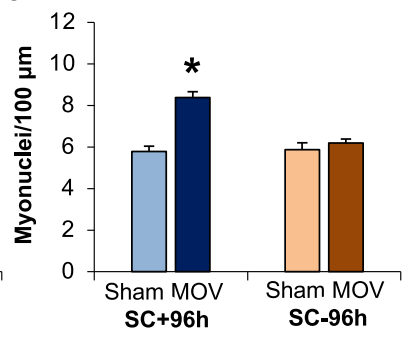

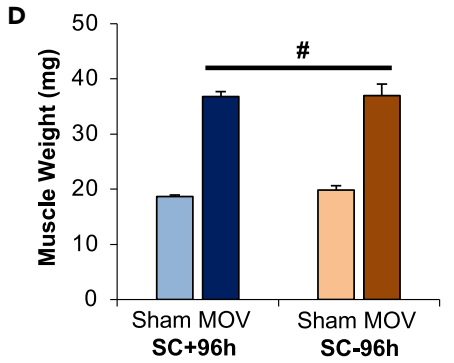

${ }^{800} 7$... Sham SC+

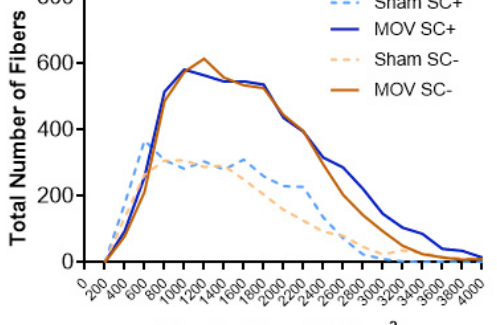

Muscle Fiber CSA $\left(\mu \mathrm{m}^{2}\right)$

$\mathbf{F}$

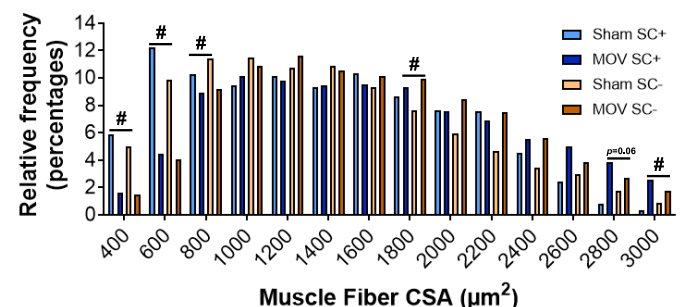

H

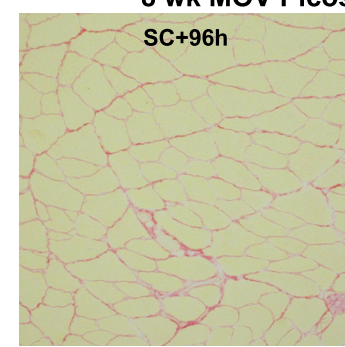

8 wk MOV Picosirius Red (PSR)

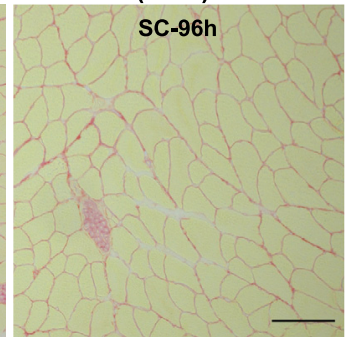

$\mathbf{G}$
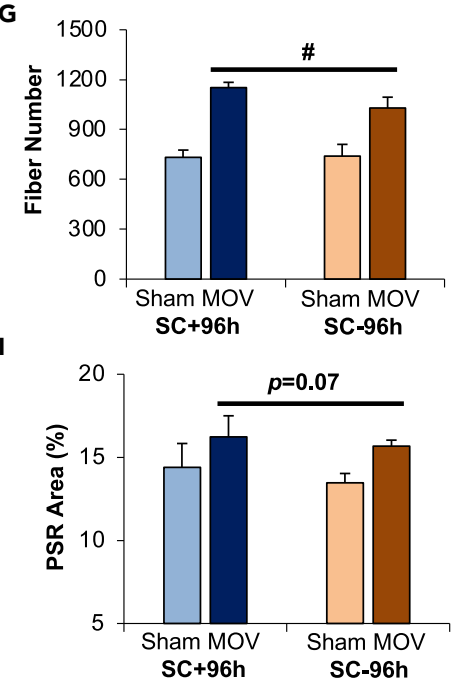

Figure 7. The presence of satellite cells (SCs) for the first $96 \mathrm{hr}$ of mechanical overload (MOV) is sufficient to control extracellular matrix deposition and support long-term hypertrophy of the plantaris muscle (A) Experimental design schematic demonstrating the Veh and Tam treatment strategy after $96 \mathrm{hr}$ of MOV (SC+96 hr and SC-96 hr, respectively) followed by 47 days of MOV (to 8 total weeks) in Pax7-DTA mice. Three mice were removed from this analysis: two in the tamoxifen-treated MOV group due to poor satellite cell depletion and one vehicle-treated MOV due to marked signs of regeneration and/or fiber splitting (numerous central nuclei and large heterogeneity in fiber size) (Murach et al., 2019), resulting in $n=4$ for sham and $n=5$ for MOV in each condition.

(B) Satellite cell quantity in Veh- and Tam-treated mice. ${ }^{\dagger} p<0.05$ effect of tamoxifen, ${ }^{*} p<0.05$ effect of MOV.

(C) Myonuclei per fiber in SC+96 hr and SC-96 hr muscles, measured in isolated single muscle fibers. $\mathrm{p}<0.05$ interaction effect.

(D) Muscle weight in the presence and absence of satellite cells. ${ }^{*} p<0.05$ effect of MOV.

(E) Total muscle fiber cross-sectional area (CSA) distribution in SC+96 hr and SC-96 hr muscles.

(F) Muscle fiber CSA presented as relative frequency. ${ }^{*} \mathrm{p}<0.05$ effect of $\mathrm{MOV}$.

(G) Fiber number on cross section, ${ }^{*} p<0.05$ effect of MOV.

(H) Representative image of extracellular matrix via picrosirius red (PSR) staining after MOV in SC+96 hr and SC-96 hr, scale bar, $100 \mu \mathrm{m}$.

(I) PSR area normalized to muscle area, $\mathrm{p}=0.07$ main effect for MOV. Data are presented as mean $\pm \mathrm{SEM}$. 
In a recent investigation, we incubated myotubes with MPC EVs and then conducted RNA-seq on the myotubes (Murach et al., 2020c). Apart from "ECM organization", pathway analysis (Herwig et al., 2016) of differentially repressed myotube genes revealed "TNF signaling" and "cytokine-cytokine receptor interaction" as the processes most downregulated by MPC EVs; specifically, Ccl2 and Ccl7 were repressed in myotubes (Murach et al., 2020c). Ccl2 and Ccl7, along with Cxcl5, were also appreciably lower in satellite cells replete relative to deplete whole plantaris muscles after 7 days of MOV (Murach et al., 2020c). Pathway analysis similarly showed "immune system" and "cytokine-cytokine receptor interaction" among the topmost downregulated processes in the muscle in the presence versus absence of satellite cells with MOV (Reactome and KEGG). Accordingly, our scRNA-seq data indicate that satellite cell regulation of chemokine gene expression in individual mononuclear cells throughout the muscle is conserved, with the most noticeable effect in FAPs. FAPs play a role in muscle mass regulation (Wosczyna et al., 2019), and the immunomodulatory function of FAPs (De Micheli et al., 2020; Oprescu et al., 2020; Santini et al., 2020), as well as the complex interplay between FAPs and immune cells in muscle repair (Lemos et al., 2015), are being recognized. Through secreted factors, we propose that satellite cells serve as intermediaries, for immune signaling, as well as fibrogenic cell function early during adaptation which ensures proper ECM remodeling and hypertrophy during long-term loading. Additionally, miR-206 delivery from satellite cell EVs may directly influence FAP behavior via regulation of Wisp1, which is associated with fibrogenic cell expansion and FAP fate progression (Ono et al., 2018; Oprescu et al., 2020; Venkatachalam et al., 2009). While typically low in fibrogenic cells (Fry et al., 2017), recent evidence suggests that miR-206 can be produced by FAPs under pathological conditions (Sandonà et al., 2020), and FAP-derived Wisp1 may be required to maintain myogenic cell function during aging (Lukjanenko et al., 2019). Satellite cell-FAP cross talk involving Wisp1 and miR-206 is likely condition dependent; however, Wisp1 is higher in whole muscle during MOV in the absence versus the presence of satellite cells (Murach et al., 2020c), which supports our observations that satellite cells signal to Wisp1-enriched FAPs during hypertrophy. Our data collectively agree with a proposed "cell circuit" framework where the early interplay between fibrogenic and inflammatory signaling, often influenced by a third cell type (in this case satellite cells), tunes fibrogenic cell behavior and dictates long-term ECM deposition and homeostasis (Adler et al., 2020).

Resident myonuclei have a robust transcriptional reserve capacity during short-term hypertrophy in adult muscle (Kawano et al., 2017; Kirby et al., 2016b; Murach et al., 2018a); however, it has been unclear whether attenuated long-term growth in the absence of satellite cells is due to a lack of myonuclear accretion or excess ECM deposition (Fry et al., 2014a, 2017). In mice depleted of satellite cells prior to experimentation, we recently reported that muscle fiber growth during running exercise ensues without excess ECM deposition but is impaired relative to satellite cell replete mice (Englund et al., 2020a, 2020b). In context with our current findings, we posit that there is likely an upper limit to the transcriptional capabilities of resident myonuclei for supporting adult muscle fiber growth (Petrella et al., 2008). This limit could be related to the stimulus (endurance and hypertrophic versus primarily hypertrophic) (Murach et al., 2020a), muscle or fiber type (Fry et al., 2014b), and/or the oxidative metabolic/protein synthetic demands placed on muscle fibers during loading (Murach et al., 2018b). While satellite cell fusion positively regulates myonuclear transcription during exercise (Englund et al., 2020a), fusion-independent satellite cell communication to fibrogenic cells (Fry et al., 2014a, 2017), muscle fibers (Murach et al., 2020c), and throughout muscle is also pro-hypertrophic. Evidence for the secretory functions of satellite cells provides an additional process that can be targeted to enhance stem cell-based therapeutic strategies for improving muscle mass or ameliorating fibrosis in disease and aging.

\section{Limitations of the study}

We provide multiple lines of evidence that indicate myogenic cells communicate with mononuclear cells throughout the muscle via EVs during hypertrophic adaptation; however, the current lack of a technology to prevent EV release in a cell-type-specific fashion means that other secretory mechanisms could in part explain some of our results. Furthermore, at earlier time points of MOV, more sensitive EV tracking tools may be required to define the extent of EV communication from satellite cells to mononuclear cells.

\section{Resource availability}

Lead contact

Further information and requests for resources should be directed to Charlotte Peterson, PhD (cpete4@ uky.edu) and John McCarthy, PhD (jjmcca2@uky.edu). 
Material availability

This work did not generate or use any new or unique reagents.

Data and code availability

The accession number for the scRNA-seq data reported in this paper is GEO: GSE168872. The code to find the proportional difference in cell populations between two samples is available as an R library on GitHub: https://github.com/rpolicastro/scProportionTest/releases/tag/v1.0.0.

\section{METHODS}

All methods can be found in the accompanying transparent methods supplemental file.

\section{SUPPLEMENTAL INFORMATION}

Supplemental information can be found online at https://doi.org/10.1016/j.isci.2021.102372.

\section{ACKNOWLEDGMENTS}

The authors wish to thank Jennifer Strange of the University of Kentucky Flow Cytometry Core and Dr. Doug Harrison of the University of Kentucky Biology Department/Genetics and Genomics Imaging Center for their technical expertise with fluorescent activated cell sorting and single-cell RNA sequencing, respectively. Partial computational support was provided by the University of Kentucky High Performance Computing complex. The authors thank Dr. Ferdinand von Walden for providing mice for this study, Dr. Yuan Wen for his technical expertise, and Dr. Eric Wang for providing resources. This work was supported by funding from the NIH National Institutes of Arthritis and Musculoskeletal and Skin Diseases (AR060701 to C.A.P. and J.J.M. and AR071753 to K.A.M), National Institute on Aging (AG049086 to C.A.P. and J.J.M. and AG063994 to K.A.M), National Institute of Diabetes and Digestive and Kidney Diseases (DK119619 to C.A.P. and J.J.M), and National Institute of General Medical Sciences (GM130349 to J.J.S.)

\section{AUTHOR CONTRIBUTION}

K.A.M., C.S.F., C.A.P., and J.J.M. designed experiments. K.A.M., B.D.P., D.W.V.P., L.T.D., I.J.V., B.D.P., C.M.D., C.R.B., C.S.F., X.F., and C.I.R. performed experiments. K.A.M., B.D.P., R.A.P., D.W.V.P., I.J.V., B.D.P., C.R.B., X.F., C.I.R., and J.J.S. analyzed data. G.E.Z. and E.E.D.-V. provided resources. K.A.M wrote the manuscript and prepared the figures. C.A.P. and J.J.M. provided funding support and supervised the study. C.A.P., J.J.M., and R.A.P. assisted with data interpretation and manuscript writing. All authors edited and approved the final manuscript.

\section{DECLARATION OF INTERESTS}

The authors have no conflicts to declare.

Received: November 25, 2020

Revised: March 8, 2021

Accepted: March 25, 2021

Published: April 23, 2021

\section{REFERENCES}

Adler, M., Mayo, A., Zhou, X., Franklin, R.A., Meizlish, M.L., Medzhitov, R., Kallenberger, S.M., and Alon, U. (2020). Principles of cell circuits for tissue repair and fibrosis. iScience 23, 100841.

Álvarez-Aznar, A., Martinez-Corral, I., Daubel, N., Betsholtz, C., Mäkinen, T., and Gängel, K. (2020).

Tamoxifen-independent recombination of reporter genes limits lineage tracing and mosaic analysis using CreER T2 lines. Trans. Res. 29, 53-68.

Aswad, H., Forterre, A., Wiklander, O.P.B., Guillaume, V. Danty-Berger, E., Jalabert, A.. Lamaziere, A., Meugnier, E., Pesenti, S., Ott, C., et al. (2014). Exosomes participate in the alteraion of muscle homeostasis during lipid-induced insulin resistance in mice. Diabetologia 57, 21552164.

Bachman, J.F., Klose, A., Liu, W., Paris, N.D., Blanc, R.S., Schmalz, M., Knapp, E., and Chakkalakal, J.V. (2018). Prepubertal skeletal muscle growth requires Pax7-expressing satellite cell-derived myonuclear contribution. Development 145, dev167197.

Bergen, V., Lange, M., Peidli, S., Wolf, F.A., and Theis, F.J. (2020). Generalizing RNA velocity to transient cell states through dynamical modeling. Nat. Biotech. 38, 1408-1414.
Berschneider, B., Ellwanger, D.C., Baarsma, H.A., Thiel, C., Shimbori, C., White, E.S., Kolb, M., Neth, P., and Königshoff, M. (2014). miR-92a regulates TGF- $\beta 1$-induced WISP1 expression in pulmonary fibrosis. Int. J. Biochem. Cell Biol. 53, 432-441.

Berschneider, B., and Königshoff, M. (2011). WNT1 inducible signaling pathway protein 1 (WISP1): a novel mediator linking development and disease. Int. J. Biochem. Cell Biol. 43, 306-309.

Chapman, M.A., Mukund, K., Subramaniam, S., Brenner, D., and Lieber, R.L. (2016). Three distinct 
cell populations express extracellular matrix proteins and increase in number during skeletal muscle fibrosis. Am. J. Physiol. Cell Physiol. 312 C131-C143.

Chappell-Maor, L., Kolesnikov, M., Kim, J.S., Shemer, A., Haimon, Z., Grozovski, J.,

Boura-Halfon, S., Masuda, T., Prinz, M., and Jung, S. (2019). Comparative analysis of CreER transgenic mice for the study of brain macrophages: a case study. Eur. J. Immunol. 50, $353-362$.

Chazaud, B., Sonnet, C., Lafuste, P., Bassez, G. Rimaniol, A.-C., Poron, F., Authier, F.-J., Dreyfus, P.A., and Gherardi, R.K. (2003). Satellite cells attract monocytes and use macrophages as a support to escape apoptosis and enhance muscle growth. J. Cell Biol. 163, 1133-1143.

Cho, D.S., and Doles, J.D. (2017). Single cell transcriptome analysis of muscle satellite cells reveals widespread transcriptional

heterogeneity. Gene 636, 54-63.

Christov, C., Chrétien, F., Abou-Khalil, R., Bassez, G. Vallet, G. Authier, F.-J., Bassaglia, Y., Shinin. V., Tajbakhsh, S., and Chazaud, B. (2007). Muscle satellite cells and endothelial cells: close neighbors and privileged partners. Mol. Biol. Cell 18. 1397-1409.

Colston, J.T. de la Rosa, S.D., Koehler, M. Gonzales, K., Mestril, R., Freeman, G.L., Bailey, S.R., and Chandrasekar, B. (2007). Wnt-induced secreted protein-1 is a prohypertrophic and profibrotic growth factor. Am. J. Physiol. Heart Circ. Physiol. 93, H1839-H1846.

Contreras, O., Rossi, F.M., and Brandan, E. (2019). Adherent muscle connective tissue fibroblasts are phenotypically and biochemically equivalent to stromal fibro/adipogenic progenitors. Matrix Biol. Plus 2, 100006

Cossetti, C., Lugini, L., Astrologo, L., Saggio, I. Fais, S., and Spadafora, C. (2014). Soma-togermline transmission of RNA in mice xenografted with human tumour cells: possible transport by exosomes. PLoS One 9, e101629.

Crewe, C. Joffin, N., Rutkowski, J.M., Kim, M. Zhang, F., Towler, D.A., Gordillo, R., and Scherer, P.E. (2018). An endothelial-to-adipocyte extracellular vesicle axis governed by metabolic state. Cell 175, 695-708, e613.

De Micheli, A.J., Laurilliard, E.J., Heinke, C.L. Ravichandran, $H$. Fraczek, $P$, SoueidBaumgarten, S., De Vlaminck, I., Elemento, O., and Cosgrove, B.D. (2020). Single-cell analysis of the muscle stem cell hierarchy identifies heterotypic communication signals involved in skeletal muscle regeneration. Cell Rep. 30, 35833595 . e3585.

Eisner, C., Cummings, M., Johnston, G., Tung, L.W. Groppa, E. Chang, C. and Rossi, F.M. (2020). Murine tissue-resident PDGFR $\alpha+$ fibro-adipogenic progenitors spontaneously acquire osteogenic phenotype in an altered inflammatory environment. J. Bone Mineral. Res. 35, 1525-1534.

Englund, D., Figueiredo, V., Dungan, C., Murach, K., Peck, B., Petrosino, J., Brightwell, C., Dupont, A., Neal, A., Fry, C., et al. (2020a). Satellite cell depletion disrupts transcriptional coordination and muscle adaptation to exercise. Function, zqaa033.

Englund, D.A., Murach, K.A., Dungan, C.M. Figueiredo, V.C. Vechetti, I.J., Jr., DupontVersteegden, E.E., McCarthy, J.J., and Peterson, C.A. (2020b). Depletion of resident muscle stem cells negatively impacts running volume, physical function and muscle hypertrophy in response to lifelong physical activity. Am. J. Physiol. Cell Physiol. 318, C1178-C1188.

Farup, J., Madaro, L., Puri, P., and Mikkelsen, U.R (2015). Interactions between muscle stem cells, mesenchymal-derived cells and immune cells in muscle homeostasis, regeneration and disease. Cell Death Dis. 6, e1830

Flaherty, S.E., 3rd, Grijalva, A., Xu, X., Ables, E., Nomani, A., and Ferrante, A.W., Jr. (2019). lipaseindependent pathway of lipid release and immune modulation by adipocytes. Science 363 989-993.

Forterre, A., Jalabert, A., Berger, E., Baudet, M. Chikh, K., Errazuriz, E., De Larichaudy, J., Chanon S., Weiss-Gayet, M., Hesse, A.M., et al. (2014). Proteomic analysis of $\mathrm{C} 2 \mathrm{C} 12$ myoblast and myotube exosome-like vesicles: a new paradigm for myoblast-myotube cross talk? PLoS One 9, e84153.

French, D.M., Kaul, R.J., D'souza, A.L., Crowley, C.W., Bao, M., Frantz, G.D., Filvaroff, E.H., and Desnoyers, L. (2004). WISP-1 is an osteoblastic regulator expressed during skeletal development and fracture repair. Am. J. Pathol. 165, 855-867.

Fry, C.S., Kirby, T.J., Kosmac, K., McCarthy, J.J., and Peterson, C.A. (2017). Myogenic progenitor cells control extracellular matrix production by fibroblasts during skeletal muscle hypertrophy. Cell Stem Cell 20, 56-69.

Fry, C.S., Lee, J.D., Jackson, J.R., Kirby, T.J., Stasko, S.A., Liu, H., Dupont-Versteegden, E.E. McCarthy, J.J., and Peterson, C.A. (2014a) Regulation of the muscle fiber microenvironment by activated satellite cells during hypertrophy. FASEB J. 28, 1654-1665

Fry, C.S., Noehren, B., Mula, J., Ubele, M.F. Westgate, P.M., Kern, P.A., and Peterson, C.A (2014b). Fibre type-specific satellite cell response to aerobic training in sedentary adults. J. Physiol. $592,2625-2635$.

Gandham, S., Su, X., Wood, J., Nocera, A.L., Alli, S.C. Milane, L., Zimmerman, A. Amiji, M., and Ivanov, A.R. (2020). Technologies and standardization in research on extracellular vesicles. Trend Biotech. 38, 1066-1098.

Gao, X., Zhang, Z., Mashimo, T., Shen, B., Nyagilo, J., Wang, $H$., Wang, $Y$. Liu, Z. Mulgaonkar, A., and Hu, X.-L. (2020). Gliomas interact with non-glioma brain cells via extracellular vesicles. Cell Rep. 30, 2489-2500. e2485

Hayman, A.R., Jones, S.J., Boyde, A., Foster, D. Colledge, W.H., Carlton, M.B., Evans, M.J., and Cox, T.M. (1996). Mice lacking tartrate-resistant acid phosphatase (Acp 5) have disrupted endochondral ossification and mild osteopetrosis. Development 122, 3151-3162.

Herwig, R., Hardt, C., Lienhard, M., and Kamburov, A. (2016). Analyzing and interpreting genome data at the network level with ConsensusPathDB. Nat. Prot. 11, 1889.

Inaoka, T., Bilbe, G., Ishibashi, O., Tezuka, K.-i. Kumegawa, M., and Kokubo, T. (1995). Molecular cloning of human cDNA for cathepsin K: novel cysteine proteinase predominantly expressed in bone. Biochem. Biophys. Res. Commun. 206. 89-96.

Inkson, C.A., Ono, M., Bi, Y, Kuznetsov, S.A. Fisher, L.W., and Young, M.F. (2009). The potential functional interaction of biglycan and WISP-1 in controlling differentiation and proliferation of osteogenic cells. Cells Tissues Organs 189, 153-157.

Inkson, C.A., Ono, M., Kuznetsov, S.A., Fisher L.W., Robey, P.G., and Young, M.F. (2008). TGF$\beta 1$ and WISP-1/CCN-4 can regulate each other's activity to cooperatively control osteoblast function. J. Cell. Biochem. 104, 1865.

Inose, H., Ochi, H., Kimura, A., Fujita, K., Xu, R. Sato, S., Iwasaki, M., Sunamura, SI, Takeuchi, I., Fukumoto, S, et al. (2009). A microRNA regulatory network of osteoblast differentiation. Proc. Nat. Acad. Sci. 106, 20794-20799.

Joe, A.W., Yi, L., Natarajan, A., Le Grand, F., So L., Wang, J., Rudnicki, M.A., and Rossi, F.M. (2010). Muscle injury activates resident fibro/ adipogenic progenitors that facilitate myogenesis. Nat. Cell Biol. 12, 153.

Kanada, M., Bachmann, M.H., Hardy, J.W Frimannson, D.O., Bronsart, L., Wang, A. Sylvester, M.D., Schmidt, T.L., Kaspar, R.L., Butte, M.J., et al. (2015). Differential fates of biomolecules delivered to target cells via extracellular vesicles. Proc. Nat. Acad. Sci. 112 E1433-E1442.

Kawano, F., Ono, Y. Fujita, R., Watanabe, A. Masuzawa, R., Shibata, K., Hasegawa, S., Nakata, K., and Nakai, N. (2017). Prenatal myonuclei play a crucial role in skeletal muscle hypertrophy in rodents. Am. J. Physiol. Cell Physiol. 312, C233C243.

Keefe, A.C., Lawson, J.A., Flygare, S.D., Fox, Z.D. Colasanto, M.P., Mathew, S.J., Yandell, M., and Kardon, G. (2015). Muscle stem cells contribute to myofibres in sedentary adult mice. Nat. Commun. 6, 7087

Kirby, T.J., McCarthy, J.J., Peterson, C.A., and Fry, C.S. (2016a). Synergist ablation as a rodent model to study satellite cell dynamics in adult skeletal muscle. Methods Mol. Biol. 1460, 43-52.

Kirby, T.J., Patel, R.M., McClintock, T.S., DupontVersteegden, E.E., Peterson, C.A., and McCarthy, J.J. (2016b). Myonuclear transcription is responsive to mechanical load and DNA content but uncoupled from cell size during hypertrophy. Mol. Biol. Cell 27, 788-798.

Krüger, J., and Rehmsmeier, M. (2006). RNAhybrid: microRNA target prediction easy, fast and flexible. Nuc Acid Res. 34, W451-W454.

La Manno, G., Soldatov, R., Zeisel, A., Braun, E. Hochgerner, H., Petukhov, V., Lidschreiber, K., Kastriti, M.E., Lönnerberg, P., and Furlan, A. (2018). RNA velocity of single cells. Nature 560, 494-498. 
Lees-Shepard, J.B., Yamamoto, M., Biswas, A.A., Stoessel, S.J., Nicholas, S.-A.E., Cogswell, C.A., Devarakonda, P.M., Schneider, M.J., Cummins, S.M., and Legendre, N.P. (2018). Activindependent signaling in fibro/adipogenic progenitors causes fibrodysplasia ossificans progressiva. Nat. Commun. 9, 1-14

Lemos, D.R., Babaeijandaghi, F., Low, M., Chang, C.-K., Lee, S.T., Fiore, D., Zhang, R.-H., Natarajan, A., Nedospasov, S.A., and Rossi, F.M. (2015). Nilotinib reduces muscle fibrosis in chronic muscle injury by promoting TNF-mediated apoptosis of fibro/adipogenic progenitors. Nat. Med. 21, 786-794.

Liu, W., Wei-LaPierre, L., Klose, A., Dirksen, R.T., and Chakkalakal, J.V. (2015). Inducible depletion of adult skeletal muscle stem cells impairs the regeneration of neuromuscular junctions. Elife 4, e09221

Lukjanenko, L., Karaz, S., Stuelsatz, P., GurriaranRodriguez, U., Michaud, J., Dammone, G., Sizzano, F., Mashinchian, O., Ancel, S., and Migliavacca, E. (2019). Aging disrupts muscle stem cell function by impairing matricellular WISP1 secretion from fibro-adipogenic progenitors. Cell Stem Cell 24, 433-446. e437.

Madisen, L., Zwingman, T.A., Sunkin, S.M., Oh, S.W., Zariwala, H.A., Gu, H., Ng, L.L., Palmiter, R.D., Hawrylycz, M.J., and Jones, A.R. (2010). A robust and high-throughput Cre reporting and characterization system for the whole mouse brain. Nat. Neurosci. 13, 133

Maeda, A., Ono, M., Holmbeck, K., Li, L., Kilts, T., Kram, V., Noonan, M., Yoshioka, Y., McNerny, E. and Tantillo, M. (2015). WNT1-induced secreted protein-1 (WISP1), a novel regulator of bone turnover and Wnt signaling. J. Biol. Chem. 290, 14004-14018

Malecova, B., Gatto, S., Etxaniz, U., Passafaro, M., Cortez, A., Nicoletti, C. Giordani, L., Torcinaro. A., De Bardi, M., and Bicciato, S. (2018). Dynamics of cellular states of fibro-adipogenic progenitors during myogenesis and muscular dystrophy. Nat. Commun. 9, 1-12.

Masschelein, E., D'Hulst, G., Zvick, J., Hinte, L., Soro-Arnaiz, I., Gorski, T., von Meyenn, F., BarNur, O., and De Bock, K. (2020). Exercise promotes satellite cell contribution to myofibers in a load-dependent manner. Skelet. Muscle 10, 21.

Matthews, B.G., Torreggiani, E., Roeder, E. Matic, I., Grcevic, D., and Kalajzic, I. (2016). Osteogenic potential of alpha smooth muscle actin expressing muscle resident progenitor cells. Bone 84, 69-77.

McCarthy, J.J., Mula, J., Miyazaki, M., Erfani, R. Garrison, K., Farooqui, A.B., Srikuea, R., Lawson, B.A., Grimes, B., Keller, C., et al. (2011). Effective fiber hypertrophy in satellite cell-depleted skeletal muscle. Development 138, 3657-3666.

Minkin, C. (1982). Bone acid phosphatase: tartrate-resistant acid phosphatase as a marker of osteoclast function. Calcif. Tissue Int. 34, 285-290.

Murach, K.A., Dungan, C.M., Peterson, C.A., and McCarthy, J.J. (2019). Muscle fiber splitting is a physiological response to extreme loading in animals. Exerc. Sport Sci. Rev. 47, 108-115.
Murach, K.A., Englund, D.A., DupontVersteegden, E.E., McCarthy, J.J., and Peterson, C.A. (2018a). Myonuclear domain flexibility challenges rigid assumptions on satellite cell contribution to skeletal muscle fiber hypertrophy. Front. Physiol. 9, 635

Murach, K.A., Fry, C.S., Kirby, T.J., Jackson, J.R., Lee, J.D., White, S.H., Dupont-Versteegden, E.E. McCarthy, J.J., and Peterson, C.A. (2018b). Starring or supporting role? Satellite cells and skeletal muscle fiber size regulation. Physiology 33, 26-38.

Murach, K.A., McCarthy, J.J., Peterson, C.A., and Dungan, C.M. (2020a). Making mice mighty: recent advances in translational models of loadinduced muscle hypertrophy. J. Appl. Physiol. $129,516-521$.

Murach, K.A., Mobley, C.B., Zdunek, C.J., Frick, K.K., Jones, S.R., McCarthy, J.J., Peterson, C.A., and Dungan, C.M. (2020b). Muscle memory: myonuclear accretion, maintenance,

morphology, and miRNA levels with training and detraining in adult mice. J. Cachexia Sarcopenia Muscle 11, 1705-1722, https://doi.org/10.1002/ jcsm. 12617.

Murach, K.A., Vechetti, I.J., Jr., Van Pelt, D.W. Crow, S.E., Dungan, C.M., Figueiredo, V.C., Kosmac, K., Fu, X., Richards, C.I., Fry, C.S., et al. (2020c). Fusion-independent satellite cell communication to muscle fibers during loadinduced hypertrophy. Function 1, zqaa009.

Murach, K.A., White, S.H., Wen, Y., Ho, A., Dupont-Versteegden, E.E., McCarthy, J.J., and Peterson, C.A. (2017). Differential requirement for satellite cells during overload-induced muscle hypertrophy in growing versus mature mice. Skelet. Muscle 7,14.

Murphy, M.M., Lawson, J.A., Mathew, S.J., Hutcheson, D.A., and Kardon, G. (2011). Satellite cells, connective tissue fibroblasts and their interactions are crucial for muscle regeneration. Development 138, 3625-3637.

Nie, Y., Sato, Y., Garner, R.T., Kargl, C., Wang, C. Kuang, S., Gilpin, C.J., and Gavin, T.P. (2019) Skeletal muscle-derived exosomes regulate endothelial cell functions via reactive oxygen species-activated nuclear factor- $\mathrm{B}$ B signalling. Exp. Physiol. 104, 1262-1273.

Ono, M., Inkson, C.A., Kilts, T.M., and Young, M.F. (2011). WISP-1/CCN4 regulates osteogenesis by enhancing BMP-2 activity. J. Bone Mineral. Res. 26, 193-208.

Ono, M., Masaki, A., Maeda, A., Kilts, T.M., Hara, E.S., Komori, T., Pham, H., Kuboki, T., and Young, M.F. (2018). CCN4/WISP1 controls cutaneous wound healing by modulating proliferation, migration and ECM expression in dermal fibroblasts via $\alpha 5 \beta 1$ and TNF $\alpha$. Matrix Biol. 68, 533-546.

Oprescu, S.N., Yue, F., Qiu, J., Brito, L.F., and Kuang, S. (2020). Temporal dynamics and heterogeneity of cell populations during skeletal muscle regeneration. iScience 23, 100993.

Ortin-Martinez, A., Tsai, E.L.S., Nickerson, P.E. Bergeret, M., Lu, Y., Smiley, S., Comanita, L., and Wallace, V.A. (2017). A reinterpretation of cell transplantation: GFP transfer from donor to host photoreceptors. Stem Cells 35, 932-939.
Patsalos, A., Pap, A., Varga, T., Trencsenyi, G. Contreras, G.A. Garai, I. Papp، Z., Dezso, B. Pintye, E., and Nagy, L. (2017). In situ macrophage phenotypic transition is affected by altered cellular composition prior to acute sterile muscle injury. J. Physiol. 595, 5815-5842.

Pawlikowski, B., Pulliam, C., Betta, N.D., Kardon G., and Olwin, B.B. (2015). Pervasive satellite cell contribution to uninjured adult muscle fibers. Skelet. Muscle 5, 42

Pearson, R., Gonzalez-Cordero, A., West, E. Ribeiro, J., Aghaizu, N., Goh, D., Sampson, R. Georgiadis, A., Waldron, P., and Duran, Y. (2016) Donor and host photoreceptors engage in material transfer following transplantation of post-mitotic photoreceptor precursors. Nat. Commun. 7, 13029.

Petrella, J.K., Kim, J.S., Mayhew, D.L., Cross, J.M. and Bamman, M.M. (2008). Potent myofiber hypertrophy during resistance training in humans is associated with satellite cell-mediated myonuclear addition: a cluster analysis. J. Appl. Physiol. 104, 1736-1742.

Rhoads, R.P., Johnson, R.M., Rathbone, C.R., Liu, X., Temm-Grove, C., Sheehan, S.M., Hoying, J.B., and Allen, R.E. (2009). Satellite cell-mediated angiogenesis in vitro coincides with a functional hypoxia-inducible factor pathway. Am. J. Physiol. Cell Physiol. 296, C1321-C1328.

Sandonà, M., Consalvi, S., Tucciarone, L., De Bardi, M., Scimeca, M., Angelini, D.F., Buffa, V., D'Amico, A., Bertini, E.S., and Cazzaniga, S. (2020). HDAC inhibitors tune miRNAs in extracellular vesicles of dystrophic muscle-resident mesenchymal cells. EMBO Rep. 21, e50863.

Santini, M.P., Malide, D., Hoffman, G., Pandey, G., D'Escamard, V., Nomura-Kitabayashi, A. Rovira, I., Kataoka, H., Ochando, J., and Harvey, R.P. (2020). Tissue-fesident PDGFR $\alpha+$ progenitor cells contribute to fibrosis versus healing in a context-and spatiotemporally dependent manner. Cell Rep. 30, 555-570. e557.

Seifi-Alan, M., Shamsi, R., Behmanesh, A., Mirfakhraie, R., Omrani, M.D., and Ghafouri-Fard, S. (2018). MIR-206 target prediction in breast cancer subtypes by bioinformatics tools. Int. J Cancer Manage 11, e69554.

Stifter, S.A., and Greter, M. (2020). STOP floxing around: specificity and leakiness of inducible Cre/ loxP systems. Eur. J. Immunol. 50, 338-341.

Summers, M.A., Mikulec, K., Peacock, L., Little, D.G., and Schindeler, A. (2017). Limitations of the Pax7-creER(T2) transgene for driving deletion of $\mathrm{Nf1}$ in adult mouse muscle. Int. J. Dev. Biol. 61 $531-536$.

Tatsumi, R., Sankoda, Y., Anderson, J.E., Sato, Y., Mizunoya, W., Shimizu, N., Suzuki, T., Yamada، M., Rhoads, R.P., Jr., and Ikeuchi, Y. (2009). Possible implication of satellite cells in regenerative motoneuritogenesis: HGF upregulates neural chemorepellent Sema3A during myogenic differentiation. Am. J. Physiol. Cell Physiol. 297, C238-C252.

Tezuka, K.-I., Tezuka, Y., Maejima, A., Sato, T. Nemoto, K., Kamioka, H., Hakeda, Y., and Kumegawa, M. (1994). Molecular cloning of a possible cysteine proteinase predominantly 
expressed in osteoclasts. J. Biol. Chem. 269, 1106-1109.

Uezumi, A., Fukada, S.-i., Yamamoto, N., Takeda, S.i., and Tsuchida, K. (2010). Mesenchymal progenitors distinct from satellite cells contribute to ectopic fat cell formation in skeletal muscle. Nat. Cell Biol. 12, 143.

Van Hove, H., Antunes, A.R.P., De Vlaminck, K., Scheyltjens, I., Van Ginderachter, J.A., and Movahedi, K. (2020). Identifying the variables that drive tamoxifen-independent CreERT2

recombination: implications for microglial fate mapping and gene deletions. Eur. J. Immunol. 50, 459-463.

Vechetti, I.J., Jr., Valentino, T., Mobley, C.B., and McCarthy, J.J. (2020). The role of extracellular vesicles in skeletal muscle and systematic adaption to exercise. J. Physiol. 599, 845-861, https://doi.org/10.1113/JP278929.
Venkatachalam, K., Venkatesan, B., Valente, A.J. Melby, P.C., Nandish, S., Reusch, J.E., Clark, R.A. and Chandrasekar, B. (2009). WISP1, a promitogenic, pro-survival factor, mediates tumor necrosis factor- $\alpha$ (TNF- $\alpha$ )-stimulated cardiac fibroblast proliferation but inhibits TNF$\alpha$-induced cardiomyocyte death. J. Biol. Chem. 284, 14414-14427.

Verma, M., Asakura, Y., Murakonda, B.S.R. Pengo, T., Latroche, C., Chazaud, B., McLoon, L.K., and Asakura, A. (2018). Muscle satellite cell cross-talk with a vascular niche maintains quiescence via VEGF and notch signaling. Cell Stem Cell 23, 530-543. e539.

Wang, H.-X., Qiu, Y.-R., and Zhong, X.-P. (2016). Intercellular protein transfer from thymocytes to thymic epithelial cells. PLoS One 11, e0152641.

Wolf, F.A., Hamey, F.K., Plass, M., Solana, J., Dahlin, J.S., Gottgens, B., Rajewsky, N., Simon, L., and Theis, F.J. (2019). PAGA: graph abstraction reconciles clustering with trajectory inference through a topology preserving map of single cells. Genome Biol. 20, 59.

Wosczyna, M.N., Biswas, A.A., Cogswell, C.A., and Goldhamer, D.J. (2012). Multipotent progenitors resident in the skeletal muscle interstitium exhibit robust BMP-dependent osteogenic activity and mediate heterotopic ossification. J. Bone Miner. Res. 27, 1004 1017.

Wosczyna, M.N. Konishi, C.T. Carbajal, E.E.P. Wang, T.T., Walsh, R.A., Gan, Q., Wagner, M.W., and Rando, T.A. (2019). Mesenchymal stromal cells are required for regeneration and

homeostatic maintenance of skeletal muscle. Cell Rep. 27, 2029-2035. e2025.

Wosczyna, M.N., and Rando, T.A. (2018). A muscle stem cell support group: coordinated cellular responses in muscle regeneration. Dev. Cell 46, 135-143. 
iScience, Volume 24

Supplemental information

Early satellite cell communication creates

a permissive environment for long-term

muscle growth

Kevin A. Murach, Bailey D. Peck, Robert A. Policastro, Ivan J. Vechetti, Douglas W. Van Pelt, Cory M. Dungan, Lance T. Denes, Xu Fu, Camille R. Brightwell, Gabriel E. Zentner, Esther E. Dupont-Versteegden, Christopher I. Richards, Jeramiah J. Smith, Christopher S. Fry, John J. McCarthy, and Charlotte A. Peterson 


\section{Supplemental Figure 1}

A

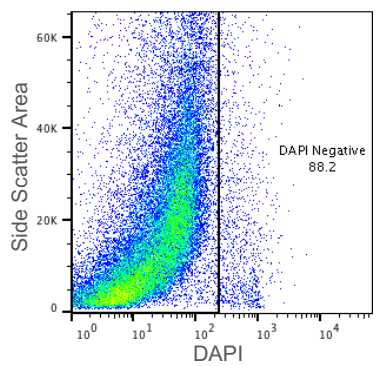

14 d MOV Tamoxifen-Treated tdT Parental
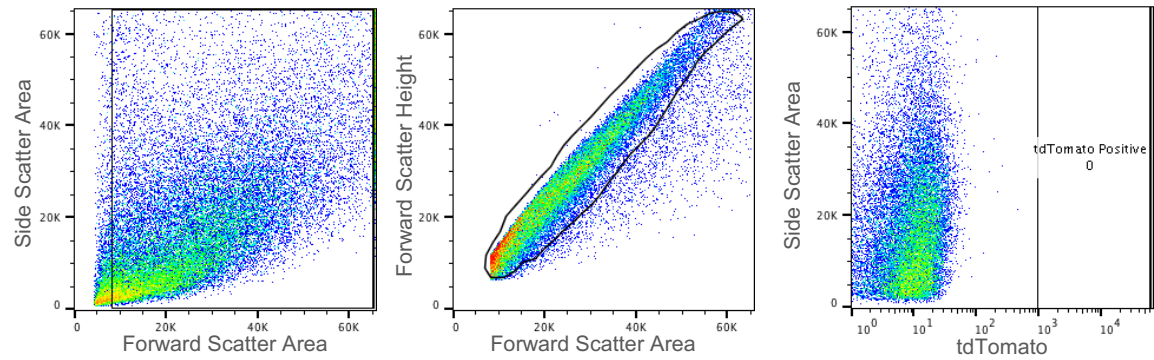

14 d MOV Vehicle-Treated Pax7-tdT (100k cells)
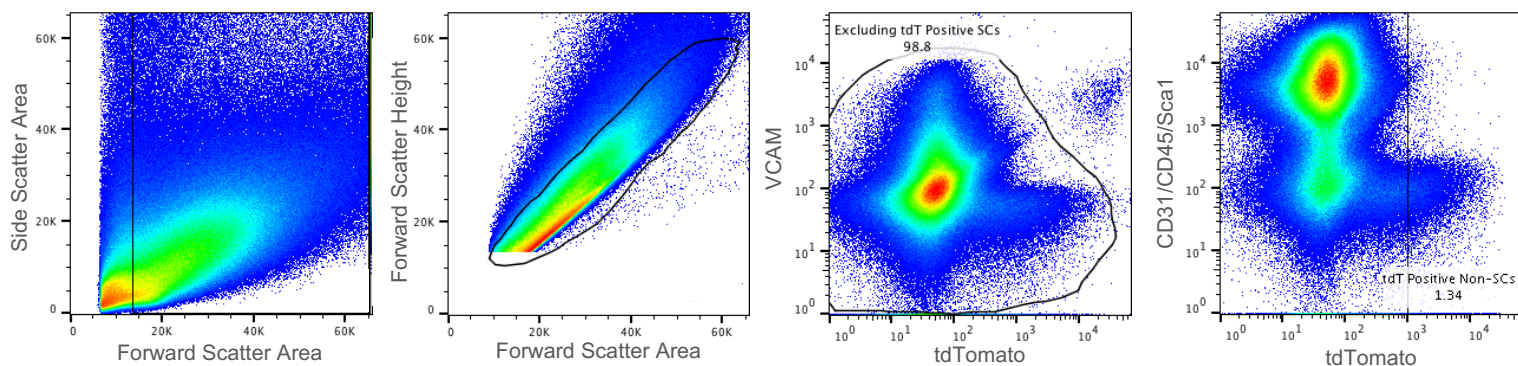

C

14 d MOV Tamoxifen-Treated Pax7-tdT (66k cells)
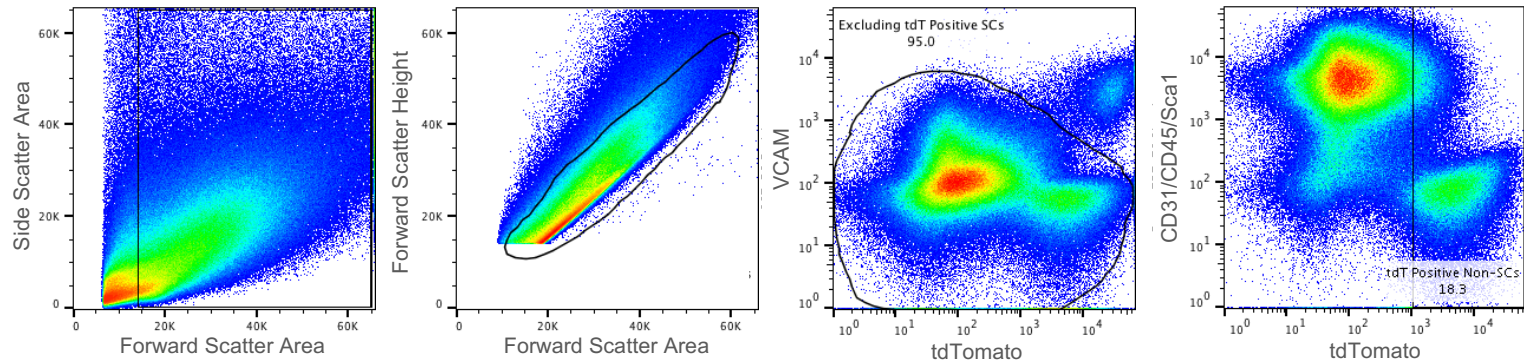

D Resting Pax7-tdT

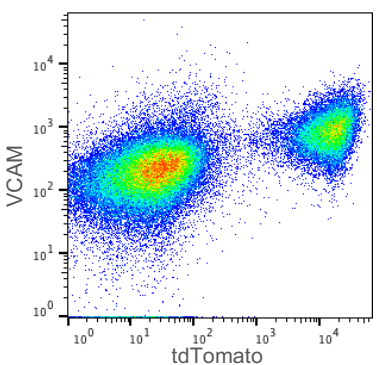

Figure S1, Flow cytometry gating strategies for 14 days of mechanical overload (MOV) experiments, Related to Figure 1.

(A) Flow cytometry plots showing a lack of tdT fluorescence in Tam-treated R26-tdT T//fl 14 day MOV plantaris muscle.

(B) Flow cytometry plots showing tdT fluorescence in Veh-treated Pax7-tdT 14 day MOV plantaris muscle; forward and side scatter area gating not shown.

(C) Flow cytometry plots showing tdT fluorescence in Tam-treated Pax7-tdT 14 day MOV plantaris muscle; forward and side scatter area gating not shown.

(D) Vcam+/tdT+ satellite cells in resting Tam-treated Pax7-tdT muscle, illustrating the specificity of tdT to satellite cells under non-stressed conditions. 


\section{Supplemental Figure 2}

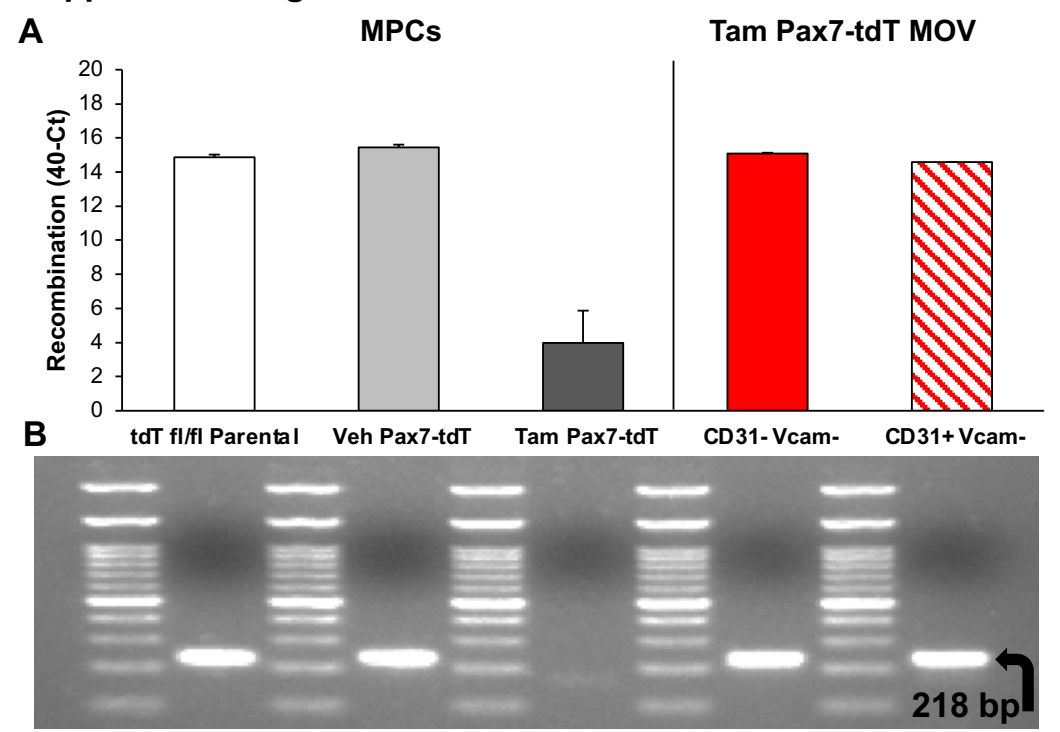

Figure S2, Presence of tdTomato (tdT) protein and mRNA in non-satellite cells (SCs) during 14 days of mechanical overload (MOV) is not attributable to off-target recombination, Related to Figure 2.

(A) Levels of $t d T$ recombination in cultured primary myogenic progenitor cell (MPC) control conditions (tdT parental, in vivo vehicle (Veh)-treated Pax7-tdT, and in vivo tamoxifen (Tam)-treated Pax7-tdT), CD31Vcam- DAPI- (viable non-satellite cells), and CD31+ Vcam- DAPI- (viable endothelial cells) populations from the Tam-treated Pax7-tdT 14 day MOV experiment in Figure 2, measured via qPCR. The specific and efficient primers from Jahn et al. (Jahn et al., 2018) were utilized, which amplify the non-recombined stop cassette, and $1 \mathrm{ng}$ of DNA was loaded in duplicate for each condition. Data are presented as 40 minus cycle threshold $(40-C t)$, mean $\pm S E$.

(B) The qPCR product from panel (A) was electroporated on a $2 \%$ agarose gel to confirm presence of a 218 bp product (see Jahn et al.), which is only absent in recombined Tam-treated Pax7-tdT cells. 
Supplemental Figure 3

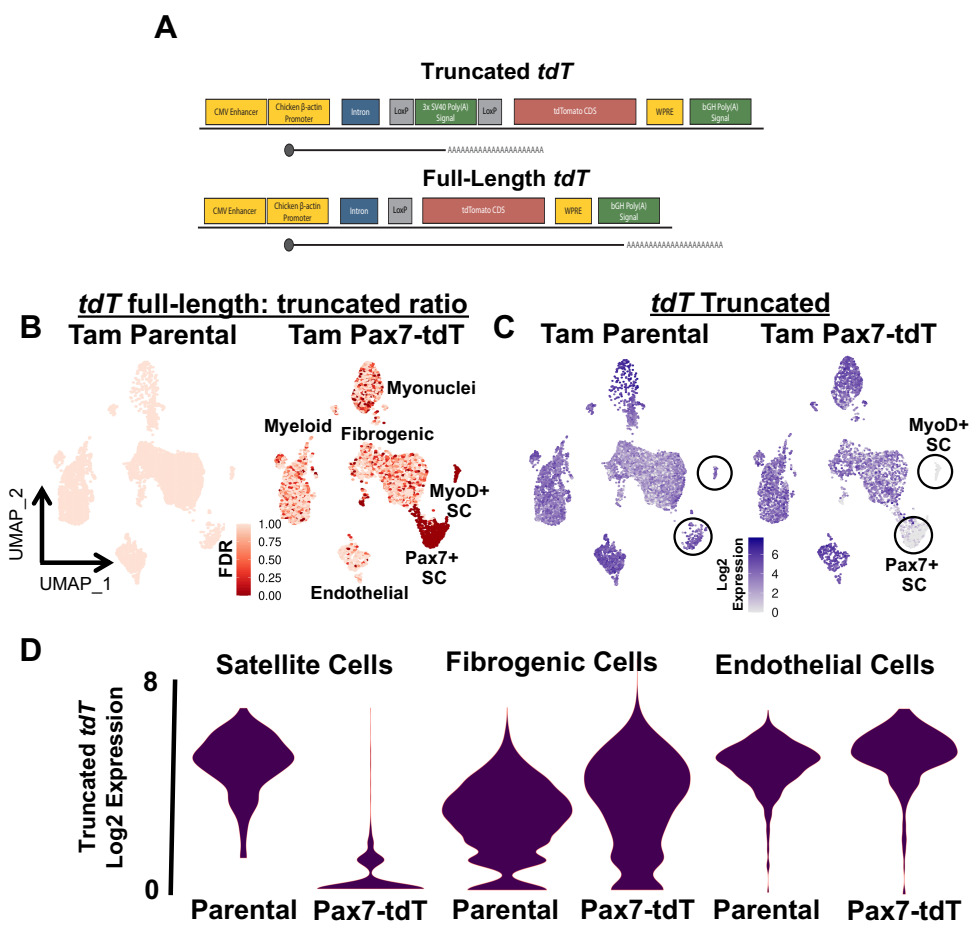

Figure S3, Control experiments providing evidence that neither stop cassette read-through nor off-target recombination explains $t d T o m a t o ~(t d T)$ expression in non-satellite cells after 14 days of mechanical overload (MOV), Related to Figure 3.

(A) Schematic illustrating truncated versus full-length $t d T$ transcript. Truncated transcript is generated by transcription up to the stop sequence, the product of which is polyadenylated and appears in 3' scRNAseq analysis. Truncated transcript is abundant in the absence of recombination, whereas full-length transcript more commonly appears once recombination removes the stop cassette.

(B) UMAPs showing abundance of full-length $t d T$ transcript in Tam-treated R26-tdT $T^{\mathrm{fl} / \mathrm{fl}} 14 \mathrm{~d}$ MOV plantaris muscle versus Tam-treated Pax7-tdT 14 day MOV plantaris muscles subjected to scRNA-seq. The ratio of truncated:full length $t d T$ was utilized to account for background levels of stop cassette read-through, and confidence in full-length $t d T$ above the levels of read-through are displayed as FDR.

(C) The same UMAPs as in (B) but showing the $\log _{2}$ counts of truncated $t d T$ transcript. There is an absence of truncated tdT in Pax7+ and MyoD+ satellite cells in Tam-treated Pax7-tdT 14 day MOV plantaris muscles, which is indicative of recombination and the loss of the stop cassette, whereas all other cell populations in parental and Pax7-tdT conditions have high levels of truncated tdT transcript. (D) Violin plots showing truncated $t d T$ transcript levels across different cell populations in parental and Pax7-tdT muscle. Truncated transcript is abundant in all cell types except satellite cells in the Pax7-tdT condition, where recombination has occurred. 


\section{Supplemental Figure 4}

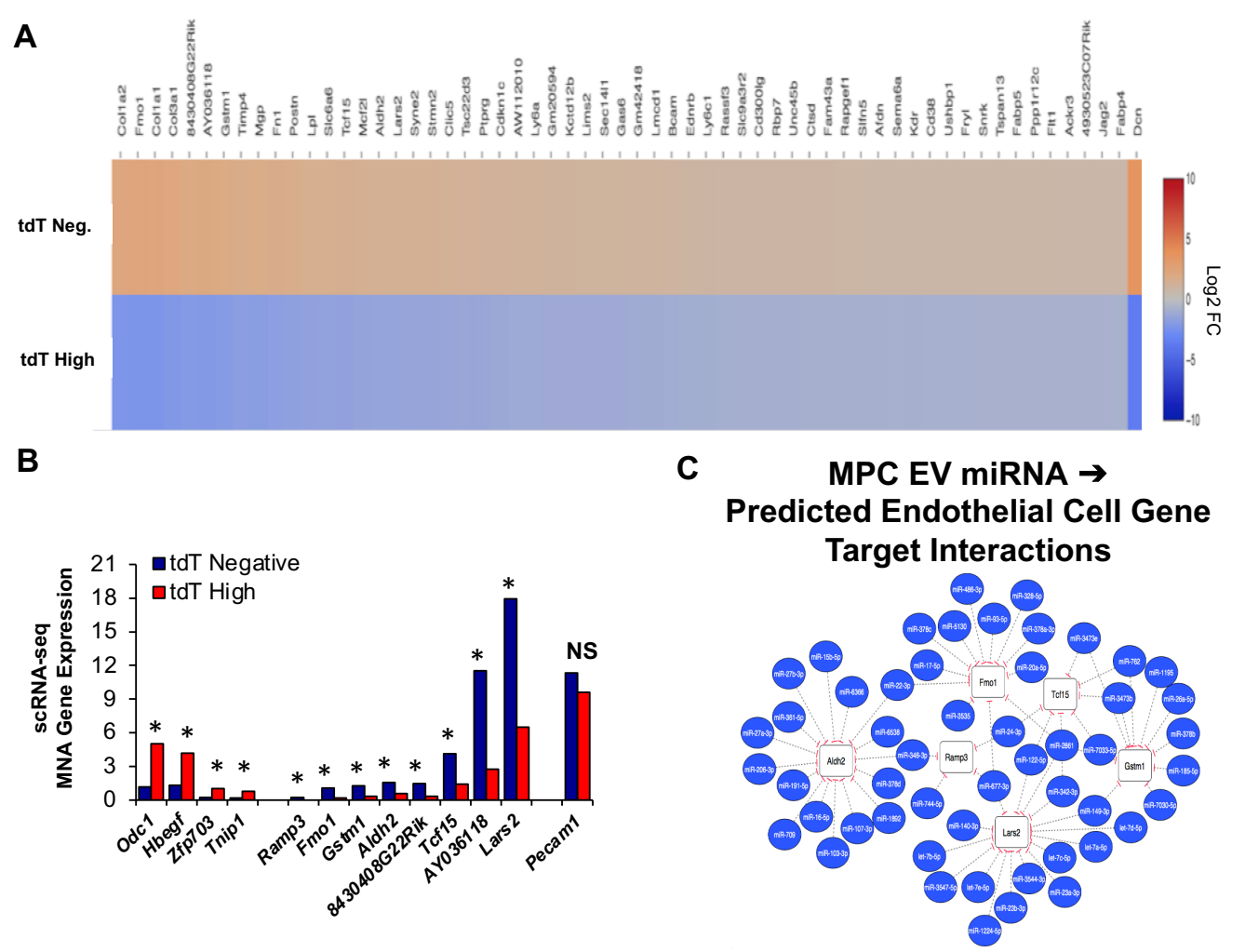

Figure S4, Transcriptional comparison of $t d T$ Tomato $(t d T)$-high $\left(\log _{2}>2\right)$ to $t d T$-null endothelial cells in Tam-treated Pax7-tdT muscle after 14 days of mechanical overload (MOV), Related to Figure 3.
(A) Heatmap showing genes (primarily ECM-related) down-regulated in endothelial cells (ECs) concomitant with higher $t d T$ levels during 14 days of MOV.
(B) Genes that were significantly elevated (adj. $p<0.05$ ) concomitant with lower levels of $t d T$. NS = not significant, MNA = median normalized average.
(C) The top 100 miRNAs enriched in MPC EVs [from (Murach et al., 2020c)] were cross-referenced against predicted targets for genes in endothelial cells that were significantly down-regulated in our scRNA-seq dataset using TargetScan, mirDB, and miRMap (miRMap score $>50$ ) databases. 


\section{Supplemental Figure 5}

A

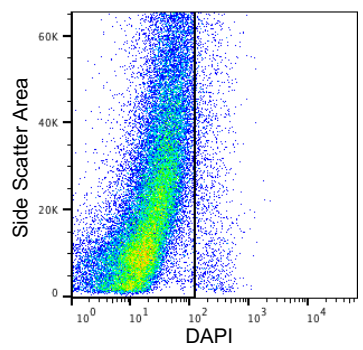

B

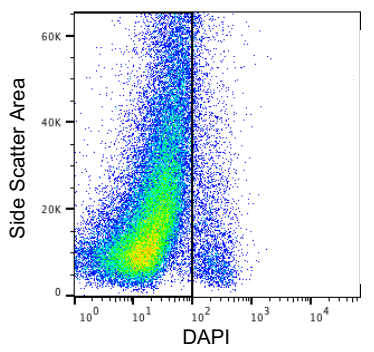

$96 \mathrm{hr}$ MOV Tamoxifen-Treated SC+
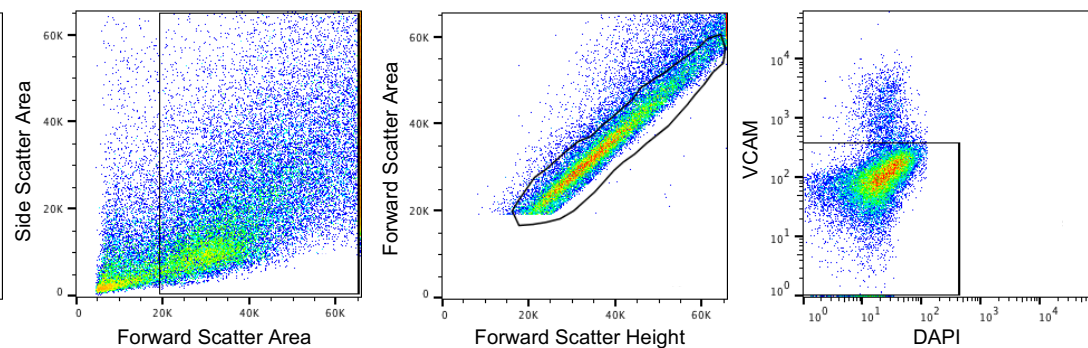

$96 \mathrm{hr}$ MOV Tamoxifen-Treated SC-
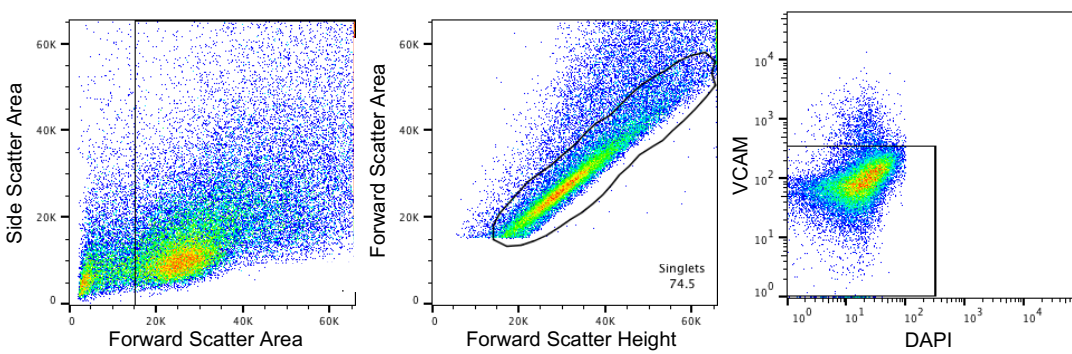

Figure S5, Flow cytometry gating for Pax7-tdT and Pax7-DTA 96 hour mechanical overload (MOV) scRNA-seq experiments, Related to Figure 4.

(A) Flow cytometry gating for Tam-treated Pax7-tdT 96 hr MOV experiment.

(B) Flow cytometry gating for Tam-treated Pax7-DTA 96 hr MOV experiment. 
TRANSPARENT METHODS

KEY RESOURCES TABLE

\begin{tabular}{|c|c|c|}
\hline REAGENT or RESOURCE & SOURCE & IDENTIFIER \\
\hline \multicolumn{3}{|l|}{ Antibodies/Stains } \\
\hline 4',6-diamidino-2-phenylindole & Life Technologies & D35471 \\
\hline Phalloidin & Invitrogen & A12379 \\
\hline aVcam/Cd106 & BioLegend & 105704 \\
\hline aCd31/Pecam & Invitrogen & $11-0311-82$ \\
\hline aCd45 & BioLegend & 103108 \\
\hline aSca1/Ly-6A/E & BD Pharmingen & 557405 \\
\hline APC-Streptavidin & BioLegend & 405207 \\
\hline aDystrophin & Abcam & ab15277 \\
\hline Picosirius Red & Electron Microscopy Sciences & 26357-02 \\
\hline Pax7 & DSHB & Pax7 \\
\hline \multicolumn{3}{|l|}{ Chemicals } \\
\hline Tamoxifen & Sigma-Aldrich & T5648 \\
\hline \multicolumn{3}{|l|}{ Deposited Data } \\
\hline Single Cell RNA Sequencing & GEO & GSE142529 \\
\hline \multicolumn{3}{|l|}{ Mouse Models } \\
\hline Pax7 CreERT2 & Jackson Laboratory & 017763 \\
\hline R26 LSL-tdTomato & Jackson Laboratory & 007905 \\
\hline R26 Diptheria Toxin A & Jackson Laboratory & 010527 \\
\hline C57BL/6J & Jackson Laboratory & 000664 \\
\hline \multicolumn{3}{|l|}{ Software } \\
\hline Zen v2.5 & Zeiss & \\
\hline Prism v8 & GraphPad & \\
\hline FlowJo v10.4.2 & Flowjo LLC & \\
\hline Loupe Cell Browser v3.1.0 & 10x Genomics & \\
\hline Cell Ranger v3.0 & 10x Genomics & \\
\hline Seurat v3.0.2 & Satija Lab & (Butler et al., 2018) \\
\hline Partek Flow & Partek & \\
\hline scVelo & Helmholtz Center Munich & (Bergen et al., 2020) \\
\hline PAGA & Helmholtz Center Munich & (Wolf et al., 2019) \\
\hline ConcensusPathDB release 34 & Max Planck Institute & (Kamburov et al., 2012) \\
\hline TargetScan release 7.2 & Whitehead Institute & (Agarwal et al., 2015) \\
\hline $\operatorname{miRDB}$ & Washington University & (Wong and Wang, 2014) \\
\hline miRMap & Geneva University & (Vejnar and Zdobnov, 2012) \\
\hline RNAhybrid & Bielefeld University & (Krüger and Rehmsmeier, 2006) \\
\hline \multicolumn{3}{|l|}{ Oligonucleotides (PCR) } \\
\hline Pax7 F & Sigma Aldrich & 5'GCTGCTGTTGATTACCTGGC'3 \\
\hline Pax7 Wild Type R & Sigma Aldrich & 5'CTGCACTGAGACAGGACCG'3 \\
\hline Pax7 Mutant R & Sigma Aldrich & 5'CAAAAGACGGCAATATGGTG'3 \\
\hline tdTomato WT F & IDT & 5'AAGGGAGCTGCAGTGGAGTA'3 \\
\hline tdTomato WT R & IDT & 5'CCGAAAAGGGAAGTC'3TCTGT \\
\hline tdTomato Mutant F & IDT & 5'CTGTTCCTGTACGGCATGG'3 \\
\hline tdTomato Mutant R & IDT & 5'GGCATTAAAGCAGCGTATCC'3 \\
\hline tdTomato Recombination F & IDT & 5'ATCATGTCTGGATCCCCATC'3 \\
\hline tdTomato Recombination R & IDT & 5'CGTGGCCGTTCATGGAGCCC'3 \\
\hline
\end{tabular}


KEY RESOURCES TABLE (cont.)

\begin{tabular}{lcc}
\hline \multicolumn{1}{c}{ REAGENT or RESOURCE } & SOURCE & IDENTIFIER \\
\hline Oligonucleotides (RT-qPCR) & & \\
\hline $18 \mathrm{~s} \mathrm{~F}$ & IDT & 5'TTCGGACGTCTGCCCTATCAA'3 \\
$18 \mathrm{~s} \mathrm{R}$ & IDT & 5'ATGGTAGGCACGGCGACTA'3 \\
Gapdh F & IDT & 5'GACGGCCGCATCTTCTTGT'3 \\
Gapdh R & IDT & 5'CACACCGACCTTCACCATTTT'3 \\
tdTomato F & IDT & 5'CCTGTTCCTGGGGCATGG'3 \\
tdTomato R & IDT & 5'TGATGACGGCCATGTTGTTG'3 \\
Wisp 1 F & IDT & 5'CAGCACCACTAGAGGAACGA'3 \\
Wisp 1 R & IDT & 5'CTGGGCACATATCTTACAGCATT'3 \\
\hline
\end{tabular}

\section{EXPERIMENTAL MODEL AND SUBJECT DETAILS}

\section{Animals}

Pax $7^{\mathrm{CreER} /+}$-tdTomato ${ }^{\mathrm{fl} /+}$ (Pax7-tdT) mice were generated by crossing male homozygous Pax $7^{\text {CreERT2 }}$ mice (Murphy et al., 2011), purchased from Jackson Laboratory, Bar Harbor, ME, with female R26 ${ }^{\text {LSL-tdTomato }}$ mice (Madisen et al., 2010), also purchased from Jackson Laboratory, as previously described by our laboratory (Murach et al., 2020). In these mice, tamoxifen treatment induces Cre activity, which deleted a stop cassette upstream of the tdT containing transgene which was inserted into the Rosa26 locus. Administration of tamoxifen to Pax7-tdT mice induces robust expression of tdT specifically in satellite cells within skeletal muscle. Pax $7^{\text {CreER/+ }}$-Diptheria Toxin A (Pax7-DTA) mice were generated the same way as Pax7-tdT mice, only using the DTA mouse (Wu et al., 2006) purchased from the Jackson Laboratory, as previously described by our laboratory (McCarthy et al., 2011). Administration of tamoxifen to these mice results in $>90 \%$ ablation of satellite cells across various skeletal muscles (Fry et al., 2014; McCarthy et al., 2011; Murach et al., 2017a). Mice were genotyped via tail snip and $\mathrm{NaOH}$ digestion, then polymerase chain reaction for 40 cycles using GoTaq $\mathrm{G} 2$ chemistry (Promega, Madison, WI, USA), followed by electroporation of the PCR product on 1.5-2.0\% agarose gel to visualize DNA bands. C57BL/6J mice were also purchased from the Jackson Laboratory for generating wild-type myogenic progenitor cells (MPCs). Experiments and animal care were performed in accordance with the University of Kentucky Institutional Animal Care and Use Committee. All mice were housed in a temperature- and humidity-controlled room and maintained on a 14:10 light:dark cycle, with standard chow and water ad libitum. All mice for in vivo experiments were $>3$ months old at the onset and were a mix of males and females, whereas experiments involving Pax7-DTA mice were $>4$ months, and the mice in Figure 7 were exclusively males. 


\section{METHOD DETAILS}

\section{Mouse treatment, synergist ablation overload surgery, and tissue collection}

Mice were injected intraperitoneally with vehicle (15\% ethanol in sunflower seed oil) or tamoxifen (2 mg/day, suspended in ethanol and sunflower seed oil) for five days, then given a minimum two-week washout period before any experimentation ensued, as previously described by our laboratory (McCarthy et al., 2011). Mice for the experiments in Figure 7 were treated with vehicle or tamoxifen for 5 days beginning 96 hours into overload. Mice underwent bilateral synergist ablation surgery to induce hypertrophy of the plantaris muscle (Fry et al., 2017; Kirby et al., 2016; McCarthy et al., 2011). Briefly, mice were anesthetized using 95\% oxygen and $5 \%$ isoflurane gas, then $\sim 1 / 3$ of the gastrocnemius/soleus complex was removed, careful not to disturb neural or vascular supply. Sham surgery involved all procedures except for excision of muscle. Following recovery from surgery, mice were euthanized via lethal dosage of sodium pentobarbital and cervical dislocation at the designated time point.

\section{Primary muscle-derived cell isolation, maintenance, and experimentation}

To isolate mononuclear cells from muscle for Pax7-tdT experiments, the detailed fluorescent activated cell sorting (FACS) protocol from the Rando laboratory was employed (Liu et al., 2015), consistent with our previous work (Murach et al., 2020). After a single cell suspension was made from fresh muscle using collagenase followed by collagenase and dispase, it was filtered through a $40 \mu \mathrm{m}$ strainer and incubated with antibodies against Vcam, Cd31, Cd45, and Sca1 at $4^{\circ} \mathrm{C}$; a biotinylated secondary antibody was used for Vcam. See Key Resources Table for antibody information. Cells were pelleted (500 x g for 5 minutes), re-suspended, and sorted using an iCyt FACS machine (Sony Biotechnology, Champaign, IL, USA). Debris and dead cells were gated out using forward/side scatter profiles and/or DAPI. For evaluating the paracrine effects of primary MPCs on primary fibrogenic cells, the cryopreserved cDNA from previouslypublished experiments was utilized (Fry et al., 2017; Fry et al., 2014). In brief, a single cell suspension was made and primary muscle-derived cells were purified via a pre-plating technique (Rando and Blau, 1994). Adherent cells (analogous to FAPs) (Contreras et al., 2019), confirmed to be >95\% Tcf4+ via immunocytochemistry (Fry et al., 2017), were maintained on uncoated plates in growth media (DMEM $+20 \%$ fetal bovine serum $+5 \mathrm{ng} / \mathrm{ml}$ basic fibroblast growth factor). The non-adherent cells from the pre-plate were transferred to and maintained on collagen-coated plates, and were confirmed to be MPCs due to being $>97 \%$ MyoD+via immunocytochemistry (Fry et al., 2017). Detailed methods on the treatment of primary fibrogenic cells with MPC conditioned media, MPC and fibrogenic cell co-cultures, fibrogenic cell 
incubations with MPC EVs, and miR-206 mimic/scramble transfection into primary fibrogenic cells are found in our previous publications (Fry et al., 2017; Fry et al., 2014). To summarize, media from C57BL/6J MPCs or primary fibrogenic cells were conditioned for 24 hours, then incubated on primary fibrogenic cells for 24 hours. MPC conditioned media (24 hr) was also used to isolate EVs via ExoQuick TC (Systems Biosciences, Mountain View, CA), as previously described by our laboratory (Fry et al., 2017; Murach et al., 2020), then incubated on primary fibrogenic cells for 24 hours (no EVs served as the control). Co-culture of MPCs with fibrogenic cells for 24 hours was accomplished using transwell inserts (co-culture with fibrogenic cells served as the control). Transfection of miR-206 mimic or scrambled control oligonucleotide into fibrogenic cells was carried out using 50 nM Lipofectamine 2000 (Life Technology) for 6 hours, then cells were harvested 24 hours later.

\section{Extracellular vesicle isolation and visualization}

In vivo tamoxifen-treated Pax7-tdT MPCs were expanded to high confluence, as previously described by our laboratory (Murach et al., 2020). MPC conditioned growth media was collected after 24-48 hours. For ultracentrifugation isolation of EVs, conditioned media was cleared of debris (3,000 x $\mathrm{g}$ for 15 minutes), diluted in PBS, then spun at 118,000 x $\mathrm{g}$ for 6 hours. The resulting EV pellet was reconstituted in $100 \mu$ of PBS and used for high-resolution imaging analysis. To visualize tdTomato-containing vesicles in solution, a $40 \mu \mathrm{L}$ sample of the vesicle suspension was placed on a glass coverslip. The fluorescence was imaged on an inverted microscope (Olympus IX81) using a 60X 1.49 NA oil immersion objective, an electron multiplying charge couple device, and $561 \mathrm{~nm}$ laser excitation. Sequential frames (10 ms) were collected for a duration of 1 minute. Images were processed and analyzed using ImageJ.

\section{RNA and DNA isolation from primary muscle cells}

For cellular RNA extraction from direct-sorted cells, the cells were lysed in TRIzol reagent, and RNA was extracted using the Zymo MiniPrep kit (Zymo Research, Irvine, CA, USA) with slight modification; the aqueous phase from TRIzol combined with 3-bromo-chloropropane was added directly to the spin column, and not the TRIzol itself (as suggested by the manufacturer). RNA concentration and quality were assessed via NanoDrop (Thermo Fisher Scientific, Waltham, MA, USA) and Bioanalyzer (Agilent, Santa Clara, CA, USA). Quantitative reverse transcription PCR (RT-qPCR) was used to detect $t d T$ message in direct-sorted cells (tdT primer previously validated in Murach et al. 2020a, 0.2 ng reactions in duplicate, normalized to 18S or Gapdh). All reactions were performed with Sybr PowerUp chemistry (Thermo Fisher Scientific) using a 
QuantStudio 3 PCR machine (Thermo Fisher Scientific), and relative gene expression analysis was performed with the $2^{-\Delta \Delta^{C T}}$ equation where the control condition was used for normalization. RNA extraction from primary fibrogenic cells for the in vitro experiments was carried out as previously described (Fry et al., 2017). After TRIzol extraction, RNA quality and concentration were assessed via NanoDrop, and cDNA synthesis was performed using qScript cDNA Supermix (Quanta Biosciences). Gene expression was analyzed via RT-qPCR as described above using $2 \mathrm{ng}$ of cDNA per reaction in duplicate, the geomean of $18 \mathrm{~S}$ and Gapdh for housekeeping purposes, and the $2^{-\Delta \Delta \mathrm{CT}}$ equation where the control condition was the normalizer. Primers for Wisp1 were from Tong et al. (Tong et al., 2016), and were validated as specific and efficient by our laboratory. For DNA extraction, alcohol was added to TRIzol used for RNA extraction and the DNA was pelleted via centrifugation, according to manufacturer instructions. DNA was then isolated using the Qiagen DNA microkit, as previously described by our laboratory for small samples (but without the use of carrier RNA) (von Walden et al., 2020). DNA concentration was then determined using Bioanalyzer and Qubit (Invitrogen), and $1 \mathrm{ng}$ of DNA was used for qPCR in duplicate, expressed as 40 minus cycle threshold. The product was then electroporated on a $2 \%$ agarose gel for 35 minutes at $75 \mathrm{~V}$. The validated primers for tdTomato recombination from Jahn et al. (Jahn et al., 2018) were utilized, which target locations upstream and downstream of the 5' LoxP site to specifically and efficiently amplify nonrecombined alleles.

\section{Muscle histology and quantification}

Histological analyses are described in detail in previous publications from our laboratory (Fry et al., 2017; Fry et al., 2014; McCarthy et al., 2011; Murach et al., 2017b). Briefly, frozen tissue was sectioned $(7 \mu \mathrm{m})$ and air-dried for a minimum of one hour. For Pax7, sections were fixed in $4 \%$ PFA then subjected to epitope retrieval using sodium citrate $(10 \mathrm{mM}, \mathrm{pH} 6.5)$ at $92^{\circ} \mathrm{C}$ for 20 minutes. Endogenous peroxidase activity was blocked using 3\% hydrogen peroxide in PBS for 7 minutes, followed by a mouse-on-mouse block (Vector Laboratories, Burlingame, VT, USA). Sections were then incubated overnight with a Pax7 antibody, followed by incubation with a biotin-conjugated secondary antibody for Pax7. The Pax7 signal was amplified using streptavidin horseradish peroxidase (SA-HRP) followed by a tyramide signal amplification fluorophore (TSA). Sections were then incubated with 4',6-diamidino-2-phenylindole (DAPI, 1:10,000) for 10 minutes. For fiber cross-sectional area, sections were incubated with an antibody against dystrophin, followed by a fluorescent secondary antibody. To analyze ECM, muscle sections were fixed for 15 minutes in Bouin's fixative in a humidified chamber at $37^{\circ} \mathrm{C}$, 
washed, then incubated in Picosirius Red (PSR) solution (0.1\% in saturated picric acid) for 2 hours at room temperature. After washing and dehydration with ethanol, sections were mounted using a xylene-based media. Muscle sections were imaged using a Zeiss upright microscope (Axiolmager M1, Oberkochen, Germany), and analyzed with Zen software or MyoVision software (Wen et al., 2017). For Pax7, entire muscle cross-sections were imaged at 20x magnification using the mosaic image stitching function in Zen. Pax7+ satellite cells were identified as Pax7+/DAPI+, and were quantified manually using tools in the Zen software (normalized to muscle fiber number). Similarly, entire muscle cross-sections were captured at 20x magnification, and muscle fiber cross sectional area was determined using semi-automated analysis software, as was muscle fiber count (Wen et al., 2017). Picosirius red images were captured at 10x, and PSR area normalized to muscle area was quantified using a semiautomated macro for hue, saturation, and lightness in the Zen software $\left(>300,000 \mu \mathrm{m}^{2}\right.$ average muscle area for sham, $>600,000 \mu \mathrm{m}^{2}$ average for MOV).

\section{Single muscle fiber isolation and myonuclear quantification}

Single fiber myonuclear counts were obtained according to previous reports (Brack et al., 2005; McCarthy et al., 2011; Murach et al., 2017b). In brief, 48-hour PFA-fixed muscles were dissected into bundles then incubated in $40 \% \mathrm{NaOH}$ for two hours at room temperature while rotating. Fibers were then washed liberally with PBS atop a $40 \mu \mathrm{m}$ strainer, gently moved into tubes using tweezers, triturated lightly until completely separated using low retention pipette tips, then dispersed on glass slides. Fibers were mounted with a glass cover slip using VectaShield with DAPI (Vector). For analysis, linear sections ( 300-500 $\mu \mathrm{m})$ from 30 randomly selected individual muscle fibers per muscle were imaged at 20x magnification using the z-stack function in Zen. Myonuclei were manually quantified and fiber length was determined using a tool in Zen. An aggregate mean value from the 30 fibers analyzed from each mouse was used for statistics.

\section{Pathway and in silico analyses}

Gene expression pathway analysis was carried out using ConcensusPathDB with the overrepresentation feature for mouse genes in KEGG, Reactome, and Wikipathway databases, and a minimum input list overlap of " 2 " and $p$-value cutoff of $p=0.01$. Unique pathways were defined as those that did not have significant overlap in genes featured in other annotated pathways, from the same or different databases. Predicted miRNA targets were assessed using TargetScan, miRDB, and miRMap (miRMap score $>50$ ) based on complementarity of seed 
sequences in the top 100 differentially expressed genes in tdT high and negative endothelial cells. RNAhybrid was used to assess miRNA affinity for 3' UTR binding (Krüger and Rehmsmeier, 2006).

\section{Single-cell RNA sequencing (scRNA-seq)}

For 14 day MOV experiments, the single cell suspensions from overloaded tamoxifen-treated Pax7-tdT or tdT parental plantaris muscles ( $n=3$ mice/6 plantaris) was cleared of debris and doublets via FACS, as described above. The pellet was washed and re-suspended in dPBS with $0.04 \%$ BSA to minimize ambient RNA and cellular aggregation, in accordance with 10X Genomics recommendations (10X Genomics, Pleasanton, CA, USA). Cell concentration was determined via hemocytometer prior to being loaded on the 10X Chromium chip. For the 96 hour MOV experiments ( $n=4$ mice/8 plantaris), cells were direct sorted into reverse transcription buffer after being cleared of debris, dead cells (DAPI), and doublets via FACS. After cells were loaded into the 10X Chromium Controller, the Single Cell 3' reagent kit applied according to the manufacturer's protocol. Libraries were prepared using version 3.0 chemistry and were sequenced on the Illumina NextSeq 500 platform, achieving a minimum of 200 million reads per sample.

\section{scRNA-seq analysis and tdT mapping}

Raw sequencing data were processed and counted to features using Cell Ranger 3.1.0 (10X Genomics) with the GRCm38 mouse assembly and transcriptome (release 99), supplemented with the Pax7-inducible tdTomato gene construct carried by the R26 $6^{\text {LSL-tdTomato }}$ mouse strain (Madisen et al., 2010) (see addgene \#22799). Cell Ranger results were visualized and analyzed in Loupe, while additional quality control filtering and analysis was conducted in Seurat version v3.1.5 and Partek Flow. Seurat filtering was set to use at least 750 genes detected and less than $25 \%$ mitochondrial gene content, and Partek was set for a minimum of 400 and maximum of 6,000 genes expressed, a minimum of $0 \%$ and maximum of $15 \%$ mitochondrial reads, and excluded features where values were $<1.0$ and were in at least $99.9 \%$ of samples. A Cell Ranger summary for each individual experiment is as follows: 96 hour MOV tamoxifen-treated Pax7-tdT (4,846 estimated cells, 19,198 total genes detected, 82.1\% fraction of reads in cells), 96 hour MOV tamoxifen-treated Pax7-DTA (5,501 estimated cells, 18,970 total genes detected, $80.0 \%$ fraction of reads in cells), 14 day tamoxifen-treated MOV Pax7-tdT parental $(6,290$ estimated cells, 21,479 total genes detected, $96.4 \%$ fraction of reads in cells), 14 day tamoxifentreated MOV tdT parental (11,360 estimated cells, 18,982 total genes detected, $94.2 \%$ fraction 
of reads in cells). Cell types were classified according to high expression levels of classical markers (e.g. Pecam1 for endothelial cells, Pdgfra for FAPs, etc.).

For RNA velocity, the BAM files from Cell Ranger were processed with Velocyto (v0.17.17) (La Manno et al., 2018) to obtain the spliced, unspliced, and ambiguous feature unique molecular identifier (UMI) counts. The matrices from Cell Ranger and Velocyto were then read into Seurat and analyzed, as previously described (Miller et al., 2020), including RNA velocity analysis with scVelo v0.2.2 (Bergen et al., 2020). Violin plots were generated in Seurat.

Based on the results of the tamoxifen-treated MOV $t d T$ parental experiment, the ratio log2(tdTfull length + 1) - log2(tdT-truncated +1$)$ for each cell was used in the calculation of the expected tdT stop-cassette readthrough, where $t d T$-full length were reads aligning to the coding sequence (CDS) and 3' UTR, and $t d T$-truncated were reads aligning to the stop-cassette. Since no recombination is expected in the parental strain, the ratios for each cell were used to create a distribution of expected values of read-through, and all cells in the parental and DTA treated strain were tested against this distribution using a non-parametric prediction interval to calculate the probability of that cell being derived from this null distribution. The resulting $p$-values were corrected for multiple comparisons using FDR. We also employed a $t d T$ assembly where just the CDS was mapped to assess the amount of mis-mapping to the 5 ' end of the transcript, which was primarily used for quantification of $t d T$ levels in the Loupe software.

\section{QUANTIFICATION AND STATISTICAL ANALYSES}

\section{Statistical Analyses}

Differences in tdT and Wisp1 mRNA via qPCR were determined using directional student's ttests, with significance set at $p<0.05$. Differences in gene expression profiles in scRNA-seq data were first determined in the Loupe Cell Browser; this software uses sSeq (Yu et al., 2013) or EdgeR (Robinson and Smyth, 2007) to determine differential gene expression within and between clusters, and gene expression was significantly different when FDR adjusted $p$ value was $<0.05$. As a second method of validation, differences in gene expression were evaluated in Partek Flow using lognormal with shrinkage and FDR step-up for multiple test correction with adjusted $p<0.05$. For the determination of $t d T$ high endothelial cells, we used $\log _{2}>2$ as a cutoff, and eliminated cells containing tdT 5', Pax7, Myod, and Myog in order to provide confidence that high levels of $t d T$ mRNA were not a consequence of mis-identification of $t d T$-expressing satellite cells. For muscle phenotyping after long-term MOV, all data were normal and 
differences between groups were analyzed via Two-Way ANOVA. When an interaction was present, a Tukey's post-hoc test was employed, and $p$ was set at $<0.05$. 


\section{SUPPLEMENTAL REFERENCES}

Agarwal, V., Bell, G.W., Nam, J.-W., and Bartel, D.P. (2015). Predicting effective microRNA target sites in mammalian mRNAs. eLife. 4, e05005.

Bergen, V., Lange, M., Peidli, S., Wolf, F.A., and Theis, F.J. (2020). Generalizing RNA velocity to transient cell states through dynamical modeling. Nat Biotech. 1-7.

Brack, A.S., Bildsoe, H., and Hughes, S.M. (2005). Evidence that satellite cell decrement contributes to preferential decline in nuclear number from large fibres during murine age-related muscle atrophy. J Cell Sci. 118, 4813-4821.

Butler, A., Hoffman, P., Smibert, P., Papalexi, E., and Satija, R. (2018). Integrating single-cell transcriptomic data across different conditions, technologies, and species. Nat Biotech. 36, 411420.

Contreras, O., Rossi, F.M., and Brandan, E. (2019). Adherent muscle connective tissue fibroblasts are phenotypically and biochemically equivalent to stromal fibro/adipogenic progenitors. Matrix Biol Plus. 2, 100006.

Fry, C.S., Kirby, T.J., Kosmac, K., McCarthy, J.J., and Peterson, C.A. (2017). Myogenic Progenitor Cells Control Extracellular Matrix Production by Fibroblasts during Skeletal Muscle Hypertrophy. Cell Stem Cell. 20, 56-69.

Fry, C.S., Lee, J.D., Jackson, J.R., Kirby, T.J., Stasko, S.A., Liu, H., Dupont-Versteegden, E.E., McCarthy, J.J., and Peterson, C.A. (2014). Regulation of the muscle fiber microenvironment by activated satellite cells during hypertrophy. FASEB J. 28, 1654-1665.

Jahn, H.M., Kasakow, C.V., Helfer, A., Michely, J., Verkhratsky, A., Maurer, H.H., Scheller, A., and Kirchhoff, F. (2018). Refined protocols of tamoxifen injection for inducible DNA recombination in mouse astroglia. Sci Rep. 8, 1-11.

Kamburov, A., Stelzl, U., Lehrach, H., and Herwig, R. (2012). The ConsensusPathDB interaction database: 2013 update. Nuc Acid Res. 41, D793-D800.

Kirby, T.J., McCarthy, J.J., Peterson, C.A., and Fry, C.S. (2016). Synergist Ablation as a Rodent Model to Study Satellite Cell Dynamics in Adult Skeletal Muscle. Skeletal Muscle Regeneration in the Mouse: Methods and Protocols. 43-52.

Krüger, J., and Rehmsmeier, M. (2006). RNAhybrid: microRNA target prediction easy, fast and flexible. Nuc Acid Res. 34, W451-W454.

La Manno, G., Soldatov, R., Zeisel, A., Braun, E., Hochgerner, H., Petukhov, V., Lidschreiber, K., Kastriti, M.E., Lönnerberg, P., and Furlan, A. (2018). RNA velocity of single cells. Nature. 560, 494-498.

Liu, L., Cheung, T.H., Charville, G.W., and Rando, T.A. (2015). Isolation of skeletal muscle stem cells by fluorescence-activated cell sorting. Nature Prot. 10, 1612-1624. 
Madisen, L., Zwingman, T.A., Sunkin, S.M., Oh, S.W., Zariwala, H.A., Gu, H., Ng, L.L., Palmiter, R.D., Hawrylycz, M.J., and Jones, A.R. (2010). A robust and high-throughput Cre reporting and characterization system for the whole mouse brain. Nature Neuro. 13, 133.

McCarthy, J.J., Mula, J., Miyazaki, M., Erfani, R., Garrison, K., Farooqui, A.B., Srikuea, R., Lawson, B.A., Grimes, B., Keller, C., et al. (2011). Effective fiber hypertrophy in satellite celldepleted skeletal muscle. Development. 138, 3657-3666.

Miller, S.A., Policastro, R.A., Sriramkumar, S., Lai, T., Huntington, T.D., Ladaika, C.A., Zentner, G.E., and O'Hagan, H.M. (2020). LSD1 promotes secretory cell specification to drive BRAF mutant colorectal cancer. bioRxiv, https://doi.org/10.1101/2020.1109.1125.313536.

Murach, K.A., Confides, A.L., Ho, A., Jackson, J.R., Ghazala, L.S., Peterson, C.A., and DupontVersteegden, E.E. (2017a). Depletion of Pax7+ satellite cells does not affect diaphragm adaptations to running in young or aged mice. J Physiol. 595, 6299-6311.

Murach, K.A., Vechetti Jr, I.J., Van Pelt, D.W., Crow, S.E., Dungan, C.M., Figueiredo, V.C., Kosmac, K., Fu, X., Richards, C.I., Fry, C.S., et al. (2020). Fusion-independent satellite cell communication to muscle fibers during load-induced hypertrophy. Function. 1, zqaa009.

Murach, K.A., White, S.H., Wen, Y., Ho, A., Dupont-Versteegden, E.E., McCarthy, J.J., and Peterson, C.A. (2017b). Differential Requirement for Satellite Cells During Overload-Induced Muscle Hypertrophy in Growing Versus Mature Mice. Skelet Muscle. 7.

Murphy, M.M., Lawson, J.A., Mathew, S.J., Hutcheson, D.A., and Kardon, G. (2011). Satellite cells, connective tissue fibroblasts and their interactions are crucial for muscle regeneration. Development. 138, 3625-3637.

Rando, T.A., and Blau, H.M. (1994). Primary mouse myoblast purification, characterization, and transplantation for cell-mediated gene therapy. J Cell Biol.125, 1275-1287.

Robinson, M.D., and Smyth, G.K. (2007). Small-sample estimation of negative binomial dispersion, with applications to SAGE data. Biostatistics. 9, 321-332.

Tong, Y., Ding, X.-B., Chen, Z.-X., Jin, S.-Q., Zhao, X., Wang, X., Mei, S.-Y., Jiang, X., Wang, L., and Li, Q. (2016). WISP1 mediates hepatic warm ischemia reperfusion injury via TLR4 signaling in mice. Sci Rep. 6, 1-11.

Vejnar, C.E., and Zdobnov, E.M. (2012). MiRmap: comprehensive prediction of microRNA target repression strength. Nuc Acid Res. 40, 11673-11683.

von Walden, F., Rea, M., Mobley, C.B., Fondufe-Mittendorf, Y., McCarthy, J.J., Peterson, C.A., and Murach, K.A. (2020). The myonuclear DNA methylome in response to an acute hypertrophic stimulus. Epigenetics. 15, 1151-1162.

Wen, Y., Murach, K.A., Vechetti Jr, I.J., Fry, C.S., Vickery, C.D., Peterson, C.A., McCarthy, J.J., and Campbell, K.S. (2017). MyoVision: Software for automated high-content analysis of skeletal muscle immunohistochemistry. J Appl Physiol. 124: 40-51. 
Wolf, F.A., Hamey, F.K., Plass, M., Solana, J., Dahlin, J.S., Gottgens, B., Rajewsky, N., Simon, L., and Theis, F.J. (2019). PAGA: graph abstraction reconciles clustering with trajectory inference through a topology preserving map of single cells. Genome Biol. 20, 59.

Wong, N., and Wang, X. (2014). miRDB: an online resource for microRNA target prediction and functional annotations. Nucleic Acid Res. 43, D146-D152.

Wu, S., Wu, Y., and Capecchi, M.R. (2006). Motoneurons and oligodendrocytes are sequentially generated from neural stem cells but do not appear to share common lineage-restricted progenitors in vivo. Development. 133, 581-590.

Yu, D., Huber, W., and Vitek, O. (2013). Shrinkage estimation of dispersion in Negative Binomial models for RNA-seq experiments with small sample size. Bioinformatics. 29, 12751282. 